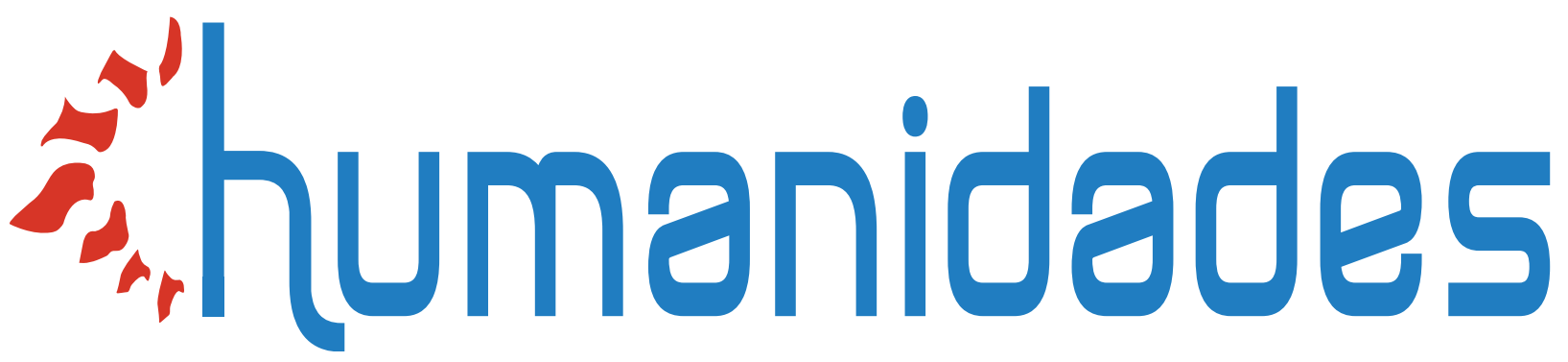

\title{
The Beatles: tradición, vanguardia... y expresividad
}

\author{
Montiel Seguí \\ Marta Vela
}

DOl: https://doi.org/I0.155 I7/h.v I0il.39660 https://revistas.ucr.ac.cr/index.php/humanidades/index 


\section{thumanidades}

Revista Humanidades

ISSN: 2215-3934

humanidades@ucr.ac.cr

Universidad de Costa Rica

Costa Rica

\section{The Beatles: tradición, vanguardia... y expresividad}

Seguí, Mg. Montiel; Vela, Dra. Marta

The Beatles: tradición, vanguardia... y expresividad

Revista Humanidades, vol. 10, núm. 1, 2020

Universidad de Costa Rica, Costa Rica

Disponible en: http://www.redalyc.org/articulo.oa?id=498060395011

DOI: https://doi.org/10.15517/h.v10i1.39660

Todos los derechos reservados. Universidad de Costa Rica. Esta revista se encuentra licenciada con

Creative Commons. Reconocimiento-NoComercial-SinObraDerivada 3.0 Costa Rica. Correo electrónico:

humanidades@ucr.ac.cr/ Sitio web: http: //revistas.ucr.ac.cr/index.php/humanidades

Esta obra está bajo una Licencia Creative Commons Atribución-NoComercial-SinDerivar 3.0 Internacional. 
Desde el arte, la literatura y la comunicación

\section{The Beatles: tradición, vanguardia... y expresividad}

The Beatles: Tradition, Avant-garde... and Expressiveness

Mg. Montiel Segui

Universitat de València - Universidad de Valencia, España

montielsegui@gmail.com

DOI: https://doi.org/10.15517/h.v10i1.39660

Redalyc: http://www.redalyc.org/articulo.oa?

iD http://orcid.org/0000-0002-6263-272X

Dra. Marta Vela

Universidad Internacional de La Rioja, España

marta.vela@unir.net

iD http://orcid.org/0000-0002-5700-6767

Recepción: 15 Septiembre 2019

Aprobación: 24 Octubre 2019

\section{RESUMEN:}

La música de The Beatles, tras su enorme éxito a través del tiempo, esconde diversos secretos que hunden sus raíces no solo en las tendencias coetáneas más evidentes -Pop Art, hippismo, cómic-, sino también en otras mucho más alejadas y sorprendentes que se refieren al manejo de las emociones, desde diversas herramientas armónicas procedentes de la música académica con la manifiesta influencia de las artes visuales, la pintura, la fotografía o la iconología sobre los álbumes del grupo. La continua búsqueda expresiva en The Beatles convirtió la música de la banda de Liverpool en una síntesis perfecta entre vanguardia y tradición a causa de la convergencia entre texto y sonido y, sobre todo, gracias al aprovechamiento de recursos tradicionales como el uso del cromatismo y de la dominante secundaria.

Palabras clave: Arte, Música, Tradición, Música Popular.

\section{Abstract:}

The music of The Beatles, after its enormous success through time, hides diverse secrets that sink their roots not only in the more evident contemporary trends - Pop Art, hippie movement, comic-, but also, in others much more remote and surprising that have to do with the handling of emotions from the harmonic tools of academic music, and with the influence of the visual arts, painting, photography or iconology on the group's albums. The continuous expressive search in The Beatles turned the music of the Liverpool band into a perfect synthesis between avant-garde and tradition because of the convergence between text and sound, and above all, thanks to the use of traditional resources as a the use of chromatism and the secondary dominant.

KeYWORDs: Art, Music, Tradition, Popular Music.

\section{INTRODUCCIÓN}

En las últimas décadas y hasta la actualidad, las emociones han cobrado una gran importancia en determinados ámbitos -la educación, la psicología, incluso, el complejo mundo de la empresa- y se nos han presentado como un elemento innovador, rabiosamente actual cuyo poder, pretendidamente, nos había pasado desapercibido. Sin embargo, conviene resaltar que el entorno humano de las emociones ha sido manipulado a través del lenguaje artístico desde tiempos inmemoriales y que, en realidad, el afecto, en un sentido barroco, el ethos de los antiguos griegos ha tenido un peso capital en determinados períodos artísticos vertebrados por una exaltación de la expresividad -la emoción - a través de distintas herramientas de raíz estética.

En este punto queremos resaltar la influencia de la música académica-seria, en el sentir de Harnoncourt ${ }^{1}$-, así como de otras tendencias artísticas - pintura, iconología, fotografía, cómic, Pop Art-, sobre la música 
de The Beatles, que se revelan, por supuesto, como uno de los secretos de su éxito, quizá no el más evidente ni el más apreciado de la actualidad, pero, no por ello, menos importante ni menos definitorio de su estilo.

\section{EL FENÓMENO BEATLES: GÉNESIS DEL GRUPO}

En la actualidad, la agrupación The Beatles representa todo un paradigma en el vasto mundo de la música pop-rock, prototipo bastante divulgado así como estimable y verdadero. La renovación sonora propuesta por la banda de Liverpool, plagada de tendencias experimentales, hizo reaccionar a buena parte de la sociedad británica de la época contra algunos de los principios tradicionales de largo arraigo histórico y, a la vez, generó toda suerte de influencias posteriores, no solo musicales, cuya huella aún se aprecia hoy en día. En relación con esta mencionada ruptura George Harrison menciona: "Nacimos durante la Segunda Guerra Mundial y conforme fuimos creciendo nos hartamos de oír hablar de ella [...]. Teníamos más ilusión en el futuro y rompimos lo que quedaba de molde victoriano respecto a actitudes, pobreza y privaciones [...]" (The Beatles, 2000, p. 201).

En el ámbito político se inició la Guerra Fría, la crisis de los misiles y la Guerra de Vietnam, bajo este contexto aparecieron grandes figuras como líderes de masas, a saber, Kennedy, Malcolm X, Luther King, Gandhi, Che Guevara, etc. Desde el plano sociológico, germinó la agitación juvenil que desembocó en la revuelta estudiantil de mayo de 1968, recordada por sus furiosos disturbios, por otro lado, afloraron los movimientos hippies contra la violencia y la propiedad. En el entorno religioso, esta frustración interior atrajo nuevos modos de espiritualidad hacia Oriente.

En la década de 1960, Inglaterra, como la mayoría de los países industrializados, se transformaba a causa de diversas coordenadas de cambio. La ciudad de Liverpool se convirtió en caldo de cultivo para las innovaciones técnicas y musicales que llegaron a través del puerto. Los muelles de Albert Dock construidos en 1864, en el marco de una sociedad posindustrial con su mezcolanza de razas y religiones, documentada desde el reinado de Isabel I, funcionaron como puerta de entrada de discos y nuevos géneros musicales - como en el caso del rock' $n$ 'roll, oriundo de Estados Unidos- que acompañaban a los marineros procedentes del extranjero y, en consecuencia, esta circunstancia actuó como foco de atracción para distintos movimientos juveniles, en palabras de John Lennon: "En Liverpool oíamos unos viejos discos de blues guarrindongo, que la gente de Gran Bretaña y Europa ni siquiera había oído nombrar, solo las zonas portuarias” (The Beatles, 2000, p. 10).

Para la formación de The Beatles, su progresiva evolución y la posterior influencia ejercida sobre la música pop-rock, fueron necesarios varios factores; en primer lugar, la obra musical de John Lennon, Paul McCartney, George Harrison y Ringo Starr aparece como deudora de autores coetáneos a ellos, tales como Buddy Holly, Fast Domino, Bill Haley and the Comets -quien lanzó el exitoso Rock Around the Clock (1955)-; Little Richard, Carl Perkins, Chuck Berry -a quien Paul McCartney veneraba por escribir su propio material, de allí que la agrupación heredara la estructura de rhythm and blues-; Lonnie Donegan con Rock Island Line (1961), con el más puro estilo skiffle, una mezcla entre rock y folk; Elvis con Heartbreak Hotel (1956), que causó estupor entre los adolescentes o el legendario Bep Bop a Lula de Gliff Gallup con Gene Vicent (1956). Estos grupos utilizaban sencillas armonías de entre tres o cuatro acordes sobre doce compases, junto con letras dirigidas a un mercado adolescente.

En segundo lugar, la formación musical de los cuatro de Liverpool carecía de cualquier tipo de estudio académico, pero la predisposición musical y la inquietud mostrada desde los inicios de la banda propició su paulatino aprendizaje. Julia Stanley, la madre de Lennon, le enseñó a tocar el banjo, lo cual justifica que John, antes de conocer a McCartney, solo utilizase las cuatro primeras cuerdas de la guitarra; sin embargo, McCartney procedía de un hábitat musical dado que su padre, Jim McCartney, tocaba el piano y la trompeta de forma autodidacta e inició a su hijo desde temprana edad. Por último, en la génesis del fenómeno beatles la afortunada sinergia entre el grupo y el productor George Martin, un músico académicamente formado y 
rodeado de técnicos de sonido como Norman Smith o Geoff Emerick, desencadenó un excelente ambiente creativo en el estudio de grabación.

En julio de 1957, Lennon actuaba en la fiesta de la parroquia de St. Peter con el grupo skiffle que había formado, The Quarry Men. Allí, como espectador, lo escuchaba McCartney acompañado por su amigo IvanVaughan mientras que Lennon tocaba y cantaba Come Go With me de Vikings, así narra Paul McCartney esta experiencia:

Era evidente que no se sabía las letras. Cantaba letras de otras canciones de blues, así que en vez de decir: come, little darling, come go with me, que es la letra verdadera, decía: down, down, down to the Penitentiary. Hacía el tipo de cosas que había oído en los discos de Big Bill Broonzy. Me pareció algo muy ingenioso y que era bastante bueno. Ese era John (The Beatles, 2000, disco 1, minuto 21).

Según Cinthia Lennon, John admitió a McCartney en la banda por sus conocimientos musicales, los cuales terminarían enriqueciendo tanto al grupo como a él mismo, por ejemplo, este podía afinar la guitarra Lennon no sabía-, además, conocía acordes nuevos y memorizaba todas las letras de las canciones. Acerca del tema, McCartney afirma: "Nos cruzábamos Liverpool por ver a alguien que supiera un acorde nuevo, nos enteramos de que había un chico que conocía el acorde Si7. Nosotros sabíamos Mi y La, son muy fáciles, pero no sabíamos Si7" (The Beatles, 2000, disco 1, minuto 15). Por su parte Cinthia Lennon dice: "Era fascinante ver cómo se enseñaban los unos a los otros nuevos acordes, cómo sacaban las melodías de las canciones populares y cómo comenzaron a crear su propio material" (Lennon, 2006, p. 41).

George entró a través de Paul gracias a su versatilidad con la guitarra. El primer baterista de la banda fue Pete Best, para la serie de actuaciones que llevaron a cabo en Hamburgo; Stuart Stutcliffe, amigo de John, fue el primer bajista del grupo. Lennon y él habían coincidido en Liverpool College of Art; Stuart, cuya obra pictórica bebía de las vanguardias históricas dentro del expresionismo abstracto con referencias a Van Gogh, Picasso, Klee, Kooning, vendió algunas pinturas tempranas a la galería John Moore con las que ganó setenta y cinco libras, que quiso invertir en pinturas y lienzos, no obstante, Lennon le persuadió para que comprara un bajo de marca Hofner y se uniera al conjunto. Su poca destreza musical le haría abandonar el grupo, en abril de 1962 muere prematuramente en Hamburgo, debido a esta circunstancia Paul asumió entonces el papel de bajista; Ringo Starr, quien estaba de gira en la misma ciudad con el grupo liverpuliano Rory and The Hurricanes, se sumó más tarde, el 18 de agosto de 1962.

De este modo, The Beatles adquirieron la praxis musical del sonido en directo en Hamburgo, tocando entre seis y ocho horas sin descanso por los libertinos círculos musicales de este núcleo portuario, incluso, en un antiguo club de striptease llamado Indra o en el Kaiserkeller, entre otros. De vuelta a Liverpool, la grabación de The Beatles con Tony Sheridan como grupo acompañante, de la cual salió el exitoso tema My Bonnie, supuso un punto de inflexión en la carrera musical de la banda. La atracción que provocaban los cuatro de Liverpool entre los adolescentes hizo que varias personas entraran en North End Music Stones (NEMS), la tienda de Brian Epstein, dispuestas a comprar su disco, por lo que este acudió interesado a escucharlos en vivo el 9 de noviembre de 1961 hasta lo que había sido, hasta entonces, un club de jazz, The Cavern. A raíz del encuentro, Epstein se convertiría en el representante de la banda de los Fab Four.

La formación de Epstein en la Real Academia de Arte Dramático, la más antigua de Gran Bretaña, junto con su interés en el diseño de moda (Goldman, 2010) parecen ser el origen de las primeras recomendaciones estéticas del mánager a los cuatro músicos: debían cambiar sus vestimentas, del cuero al traje, hacer una reverencia después de cada actuación y cortar los extremos sobrantes de las cuerdas de las guitarras, entre otras indicaciones sobre modales, todo ello, con el fin de obtener una puesta escena adecuada (The Beatles, 2000, p. 67). En 1961, Epstein logró una audición con la Decca Records que resultó fallida, hasta que, finalmente, consiguieron una prueba para Parlophone, el sello filial de Electrical and Musical Industries (EMI) donde el agente A\&R, Martin, los contrató.

"En 1962, era muy poco frecuente que los artistas que grababan discos escribieran sus propias canciones, particularmente sus primeros singles" (Dowlding, 1995, p. 26). Por esta razón, Martin les sugirió el tema How 
do You do It grabada por The Beatles el 4 de septiembre de 1962, aunque nunca editada, la cual pasó a formar parte del repertorio de Gerry And The Pacemarkers alcanzando el número uno pronosticado por Martin:

En aquella época era normal encontrar material para artistas yendo a Tin Pan Alley y escuchando las mercancías de los editores discográficos. Aquello formaba parte de mi vida diaria. Pasaba mucho tiempo buscando canciones, y lo que quería para The Beatles era un gran éxito. Estaba convencido de que How Do You Do It era una canción de éxito (The Beatles, 2000, p. 77).

Love me Do "McCartney (.7) y Lennon (.3) 2" (Dowlding, 1995, p. 26), el primer sencillo de The Beatles publicado el 5 de octubre de 1962 se alzó hasta el puesto diecisiete en las listas de éxitos británicas (Hertsgaard, 1995). En cuanto a esta grabación Goldman refiere:

Aquella fue la decisión más importante de la carrera de grabación de los Beatles, porque no solo despegaron con el pie derecho, sino que establecieron un precedente enormemente importante para otras bandas que venían detrás, con el resultado de que el rock británico pronto se convirtió en música creada en su totalidad por ejecutantes (Goldman, 2010, p. 56).

El primer sencillo número uno de The Beatles en el índice de ventas del Reino Unido llegó con Please Please $M e$, compuesto por Lennon y grabado en EMI el 11 de septiembre de 1962 (Dowlding, 1995) después de variar el tempo lento del sencillo original a una velocidad más rápida, sugerencia, de nuevo, procedente de Martin (The Beatles, 2000).

\section{3. ÉXITO E INNOVACIÓN: TRADICIÓN Y VANGUARDIA}

Sin duda, la formación académica de Martin fue fundamental en la progresión musical de The Beatles. Había estudiado Teoría Musical en Guildhall School of Music, Composición, Orquestación, Piano y Oboe. Pero, además, tenía una personalidad musicalmente abierta y dispuesta a incorporar nuevas sonoridades (Hertsgaard, 1995) provenientes de la nueva estética musical electrónica que había comenzado a gestarse a partir de 1945 en el continente.

Los éxitos se fueron sucediendo. She loves you (1963) con autoría de "Lennon (.5) y McCartney (.5)" (Dowlding, 1995, p. 39) lanzaba un mensaje directo y, por tanto, diferente al resto de las letras adolescentes sobre el amor que se habían escrito hasta entonces, estaba en tercera persona y decía directamente: "ella te quiere". La decisión de emplear en la armonía una sexta añadida al final del tema (Everett, 2013) fue algo inusual para la música popular de entonces; algo similar ocurrió con la canción que dio título al álbum $A$ Hard Day's night "Lennon (1.00)" (Dowlding, 1995, p. 64), editado en 1964 con el tañido de un acorde -que se observa en la Figura 1- que podría interpretarse como Fadd9 (con la novena mayor, la séptima mayor y la sexta añadida), donde Harrison hizo uso de una guitarra Rickenbacker 360/12 de doce cuerdas. 


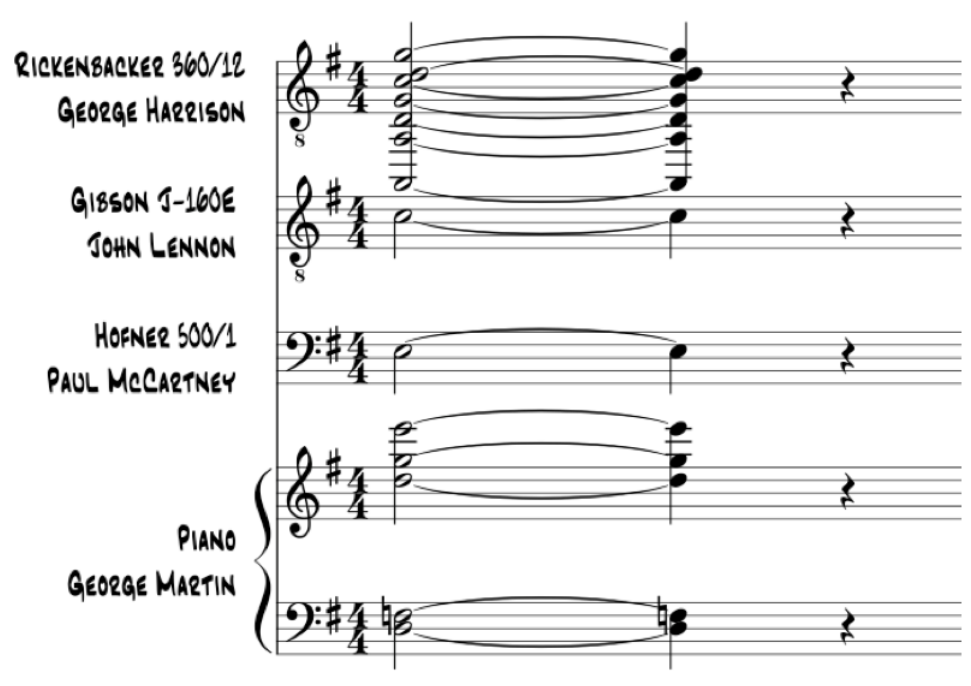

Figura 1.

Lennon \& McCartney, A hard day's night, acordeinicial.

Los Beatles entraron en el mundo cromático con simples dominantes secundarias, que escucharon en los puentes de Carl Perkins y en las piezas de vaudeville que McCartney conocía. Aparecieron a finales de 1961 con "Like Dreamers Do" y 1962 con la coda de "Little Girl". Para ese año, los acordes con notas agregadas se usaban asociados a una imagen, como en el uso de V7/VI, que atribuye el color verde a los celos en "You Can't Do That" [...]. A Lennon le gustaban las líneas cromáticas descendentes y el color de los acordes disonantes que dominaban en el puente de "It Won't Be Long", la coda de "Tell Me Why" [...]. Lennon compuso un breve pero impresionante efecto cromático que contenía una tonificación de III\#/V digna de Liszt (Everett, 2013, p. 46).

En diciembre de 1963, William Mann, el crítico de música clásica del periódico The Times, elogiaba la música de The Beatles en el artículo What Songs The Beatles Sang:

But harmonic interest is typical of their quicker songs, too, and one gets the impression that they think simultaneously of harmony and melody, so firmly are the major tonic sevenths and ninths built into their tunes, and the flat submediant key switches, so natural is the Aeolian cadence at the end of Not a Second Time (the chord progression which ends Mahler's Song of the Earth) (Mann, 1963, párr. 6) ${ }^{3}$.

El grupo se había convertido en un fenómeno social, grabó Beatles for Sale con ocho temas originales y seis temas versionados de sus autores predilectos. Con el álbum Help, editado el 6 de agosto de 1965, sobrepasaron el millón de pedidos anticipados para la reedición norteamericana, "la primera vez que ocurría esto en la industria discográfica” (Dowlding, 1995, p. 91). You've Got to Hide your Love Away y Yesterday, incluidas en el disco, fueron las primeras canciones en las que colaboraron músicos externos.

Por su parte, Rubber Soul, editado el 6 de diciembre de 1965, fue el primer álbum abierto a una nueva concepción estética que conciliaba el Long Play (LP) como una unidad artística, tanto en lo concerniente al material musical como al programa icónico-visual de la portada. La representación figurada dispuso una estrecha relación entre la imagen y la música del interior del disco convirtiéndose en un ítem recurrente en la obra de The Beatles. De este modo, la imago de portada -véase la Figura 2- se encuadra en un plano contrapicado donde los autores se asoman al espectador; el texto, en el margen superior izquierdo, a modo de gran grafito, se integra como bocadillo adoptado del mundo del cómic, adjetivando una ligera anamorfosis en lo icónico y en el signo verbal. 


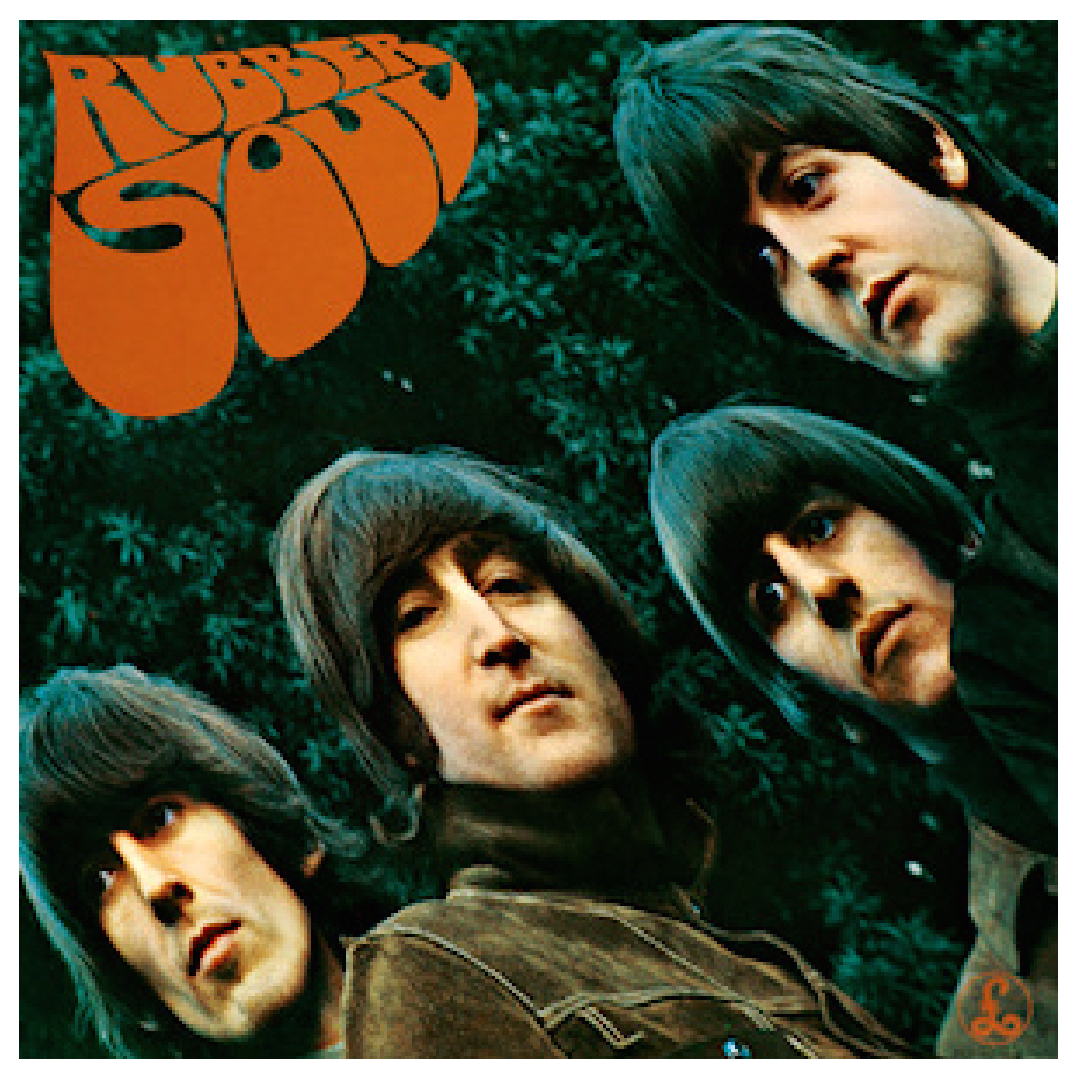

Figura 2.

Rubber Soul, 1965 (fotógrafo, Robert Freeman; diseño gráfico, Charles Front)

A partir de este hito se creó un precedente en la elaboración de carátulas de otros artistas, ya que el elemento de integridad entre el continente y el contenido llegó a ser una manifestación artística de primer orden. Sobre el álbum mencionado George Harrison dice: "En Rubber Soul estaban preparados para cambiar de rumbo. Al principio estuvieron muy influidos por el rhythm and blues americano. Creo que el llamado "sonido beatle" se debía en parte a que Liverpool era un puerto" (The Beatles, 2000, p. 194).

En este disco destacaron temas como la balada Michelle de "McCartney (.7) y Lennon (.3)" (Dowlding, 1995, p. 113) con la mezcolanza de la lengua francesa y la inglesa; Nowegian Wood (This Bird Has Flown), "Lennon (.8) y McCartney (.2)" (Dowlding, 1995, p. 110); el primer tema en que Harrison utilizó un sitar a petición de Lennon, imitado, a continuación, por "Brian Jones de los Rolling Stones ("Paint It Black", mayo de 1966), Donovan (“Sunshine Superman”, julio de 1966), Jimmy Page, el futuro Yardbird” (Everett, 2013, p. 75); Rain, con autoría de "Lennon (1.00)" (Dowlding, 1995, p. 122), utilizó el primer reverter incorporado en un disco a lo cual se expresó Lennon: "la primera grabación hacia atrás jamás incluida en un disco. Antes que Hendrix, antes que The Who, antes que ningún hijo de puta" (The Beatles, 2000, p. 212); la introspectiva In my Life de "Lennon (.65) y McCartney (.35)" donde Martin grabó el solo intermedio de teclado barroco. Por otra parte, "agregó piano, celesta, Hammond B-3 o armonio a quince canciones durante la grabación de Rubber Soul” (Everett, 2013, p. 50).

En este punto se advertía una creciente madurez musical y, sobre todo, un cambio en las letras mucho más intimistas y elaboradas en comparación a la etapa inicial, con una evocación directa hacia el estilo textual de Bob Dylan (Julià, 1996). Lennon fue un ávido lector de autores como Lewis Carroll, Edgan Allan Poe o Robert Louis Stevenson (Hertsgaard, 1995), por ejemplo, Alicia en el país de las maravillas sería una influencia directa en letras como Lucy in the Sky with Diamonds del álbum Stg. Peppers.

Así pues, The Beatles se habían convertido en músicos de estudio. En su siguiente álbum, Revolver, editado el 5 de agosto de 1966, exploraron aún más las posibilidades creativas de la sonorización: "prácticas de 
grabación como las cintas invertidas, el cambio de fase artificial, los timbres electrónicamente alterados, los efectos de sonido y una nueva imaginería estéreo" (Everett, 2013, p. 111).

Entonces se empezaron a utilizar procedimientos ligados a la idea de musique concrète dilucidada por Pierre Schaeffer, derivados de la manipulación de sonidos en el estudio: "[...] grabé a Harrison tocando una sola nota en el enorme instrumento [la tambura] (usando una vez más la técnica de acercar los micrófonos) y lo convertí en un loop. Terminó siendo el sonido que da inicio al tema” (Emerick y Massey, 2011, p. 130). Incluso, los Fab Four trabajaron sus propios loops fuera del estudio, Mc Cartney consiguió sonidos de gaviotas o copas de vino distorsionadas.

Geoff Emerick fue el nuevo ingeniero de sonido,quien junto al grupo colaboró en la insurrecta Tomorrow Never Knows (con un esquema de C, C/Bb, C): "Las canciones de un solo acorde se estaban haciendo cada vez más populares en aquellos primeros y embriagadores tiempos de la psicodelia” (Emerick y Massey, 2011, p. 22). Lennon pidió para este tema que su voz sonara como la del Dalai Lama por lo que Emerick tuvo que ingeniárselas dentro del estudio y trabajar con el material disponible en los estudios EMI de Abbey Road:

El órgano Hammond del estudio estaba conectado a un sistema llamado Leslie, una gran caja de madera que contenía un amplificador y dos altavoces giratorios, uno que canalizaba las frecuencias bajas y graves y otro que canalizaba las frecuencias altas y agudas. El efecto de aquellos altavoces giratorios era en gran parte el responsable del sonido característico del órgano Hammond. Casi podía oír mentalmente cómo sonaría la voz de John si saliera de un Leslie (Emerick y Massey, 2011, p. 22).

Por otro lado, McCartney siempre mostró un gran interés hacia el arte de vanguardia, se rodeaba de círculos intelectuales y acudía a conciertos de música académica en donde se interpretaban obras de Stockhausen, Berio y Cage. "Fue McCartney quien introdujo a los Beatles en el mundo de Stockhausen y Bach, lo que llevó a una revolución en la capacidad expresiva de la música rock dominante" (Everett, 2013, p. 35). De esta forma habla McCartney acerca de lo que presenciaba en dichas interpretaciones musicales:

Oí hablar de artistas como John Cage, y de que acababa de presentar una pieza musical llamada 4’33” (que es un silencio absoluto), durante la cual, si alguien del público tosía, él decía: “¿Veis?” O si alguien silbaba, decía: “¿Veis?” No es silencio... es música [...] Escuchaba a Stockhausen; sus piezas eran todo plink-ploks e ideas interesantes. Pensamos que quizás a nuestro público no les molestase un pequeño cambio (The Beatles, 2000, p. 212).

A day in the Life, "Lennon (.6) y McCartney (.4)" (Dowlding, 1995, p. 175) sorprendió con un glissando orquestal dirigido por David McCallum:

Martin [...] escribió el esqueleto de una partitura para el contrapunto aleatorio al estilo Penderecki que haría que cada uno de los miembros de la orquesta comenzara pianissimo en la nota más baja disponible, subiera poco a poco con unas pocas notas guías a lo largo del camino y concluyera glissando junto con todos los otros en un fortissimo sobre la nota más alta posible de la triada de Mi Mayor (Everett, 2013, p. 181).

De este modo, The Beatles podían interesarse por sofisticadas canciones al mismo tiempo que componer temas como la sencilla Yellow Submarine, con autoría de “McCartney (.8) y Lennon (.2)” (Dowlding, 1995, p. 134) e interpretada por Ringo Starr, donde se suceden toda una serie de sonidos acuáticos, que "por increíble que parezca, esta divertida pieza necesitó dos veces más tiempo de estudio que el primer LP completo de los Beatles" (Everett, 2013, p. 98). Los conocimientos de Martin sobre experimentación con pistas electrónicas y, de nuevo, la influencia de la musique concrète, situarían aún más al grupo dentro de las corrientes vanguardistas de la época, en palabras de Martin: "cuando llegó Sgt. Pepper quisieron usar hasta el último truco del manual. Aceptaron todo lo que se me ocurría" (The Beatles, 2000, p. 242).

El álbum Sgt. Pepper's Lonely Hearts Club Band de 1967 que llegó en simultáneo al verano del amor hippie sentaba, nuevamente, precedentes sobre la portada de los LP en cuestiones de sincretismo de música y diseño. De hecho, el programa visual de la carátula merecería ser estudiado desde metodologías panofskianas (Panofsky, 1972) -debido al alcance del tema, tipo iconográfico, esquema compositivo, tema de encuadre, obsérvense las Figuras 3 y 4-, que descubren una posible influencia de Eugène Disdèri (1819-1889) en su obra Mosaic d'artistes (1865), en donde observamos una tarjeta postal nutrida de importantes personajes; un 
resultado similar obtuvieron The Beatles cuando incluyeron en la imagen a ídolos populares como Marilyn Monroe, Charles Chaplin, Albert Einstein, Karlheinz Stockhausen, Oscar Wilde, Mae West, etc. Además, por primera vez, se incluían las letras de las canciones en un álbum pop y cada una de estos temas sonaba de manera concatenada con el siguiente sin irrupciones.

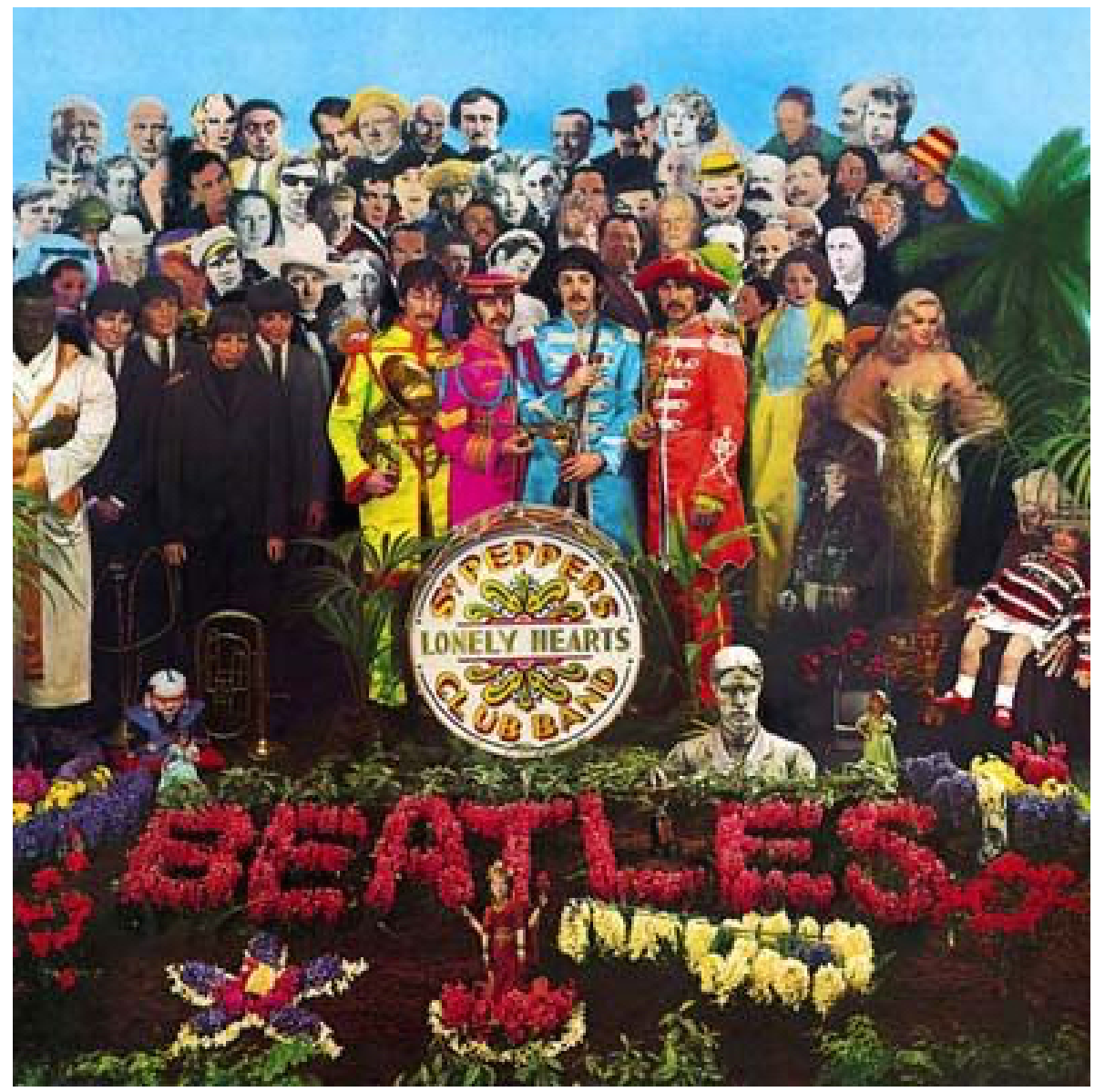

Figura 3.

Stg. Pepper's, 1967 (fotógrafo, Michael Cooper; director artístico Robert Fraser). 


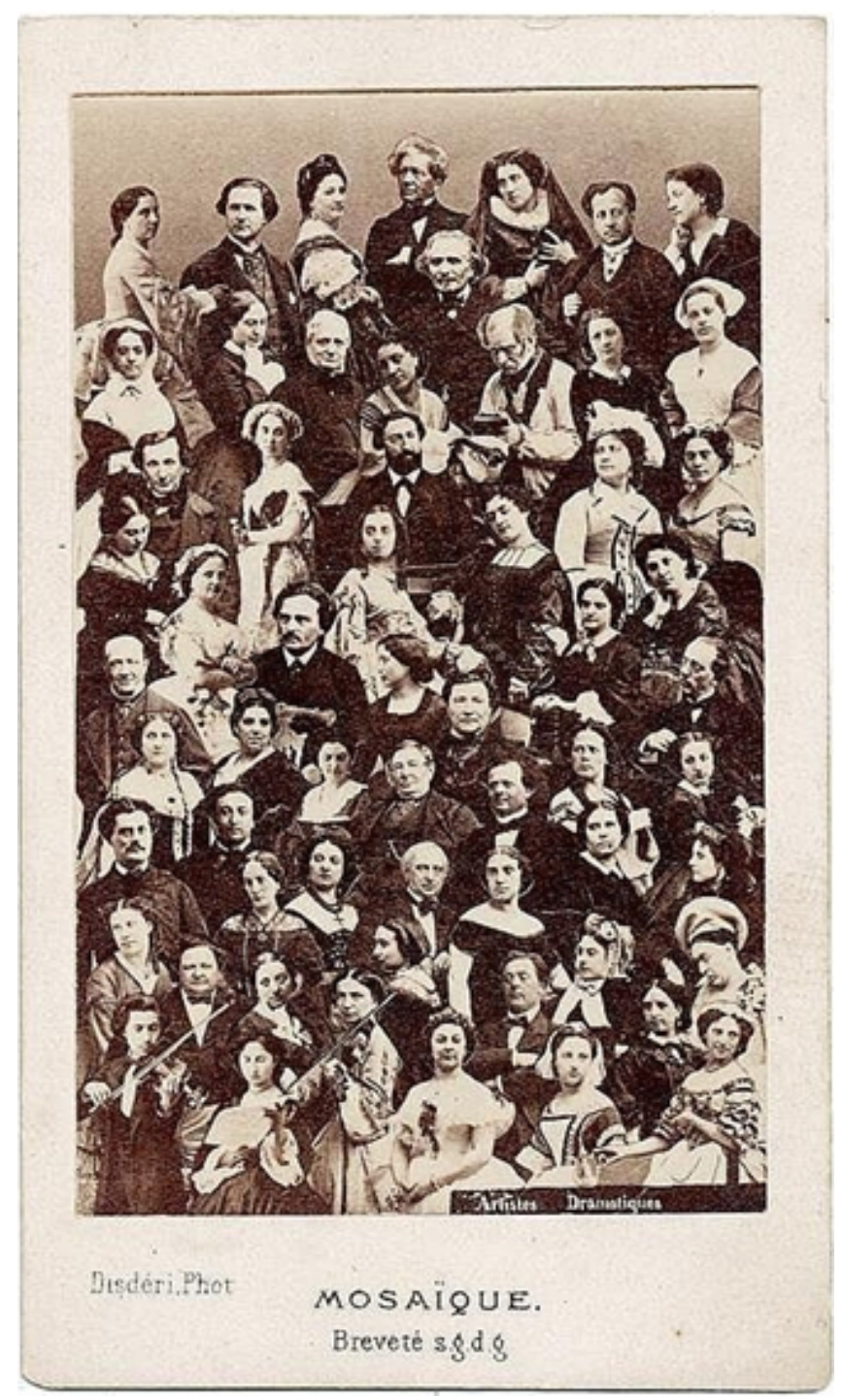

Figura 4 .

Eugène Disdèri, Mosaic d'artistes, 1865.

Sgt. Pepper's se muestra como una broma dadaísta de gran expresividad frente a las restricciones académicas, imbuido de cierta nostalgia del pasado. Los mitos icónicos son recortes de fotografías y aparecen pegados, sin orden, como un collage; la portada rinde tributo al Pop Art, a la sociedad de consumo y, por su parte, el horror vacui no permite una recreación de la vista debido al gran impacto visual que produce el abigarramiento de personas y colores; los autores aparecen a la izquierda, estáticos y grises como sin vida; centraliza la imagen el enorme tambor y el color fauvista de los cuatro componentes de The Beatles; un cielo azul cierra la composición horizontal y obliga al espectador a concentrar la mirada en los artistas, cantantes y autores, consiguiendo un efecto de posado sobre el escenario. "Había, por tanto, cierto sentido de distanciamiento irónico en sus creaciones antiartísticas. En las obras de los artistas Pop no hay cólera, ni ironía ni distanciamiento, porque no hay entrega a nada fuera de la fabricación del objeto en sí” (Heard, 1993, pp. 546-547).

Otras portadas merecen atención por su iconicidad. En el caso del álbum de 1964, A Hard Day's Night, citado en líneas anteriores, la imagen, en distintas viñetas, se presenta estática o en movimiento donde cada recuadro representa una historia a la vez que divide la secuencia. Se trata de la técnica fotográfica conocida como cronofotografía surgida a finales del siglo XIX y precursora del cine. En este sentido, la organización 
del discurso visual en la obra de Marcel Duchamp de 1912, Desnudo bajando la escalera $n^{\circ} 2$, ilustra, de igual manera, la imagen en serie hacia el conjunto de una realidad única, como muestran las Figuras 5 y 6:

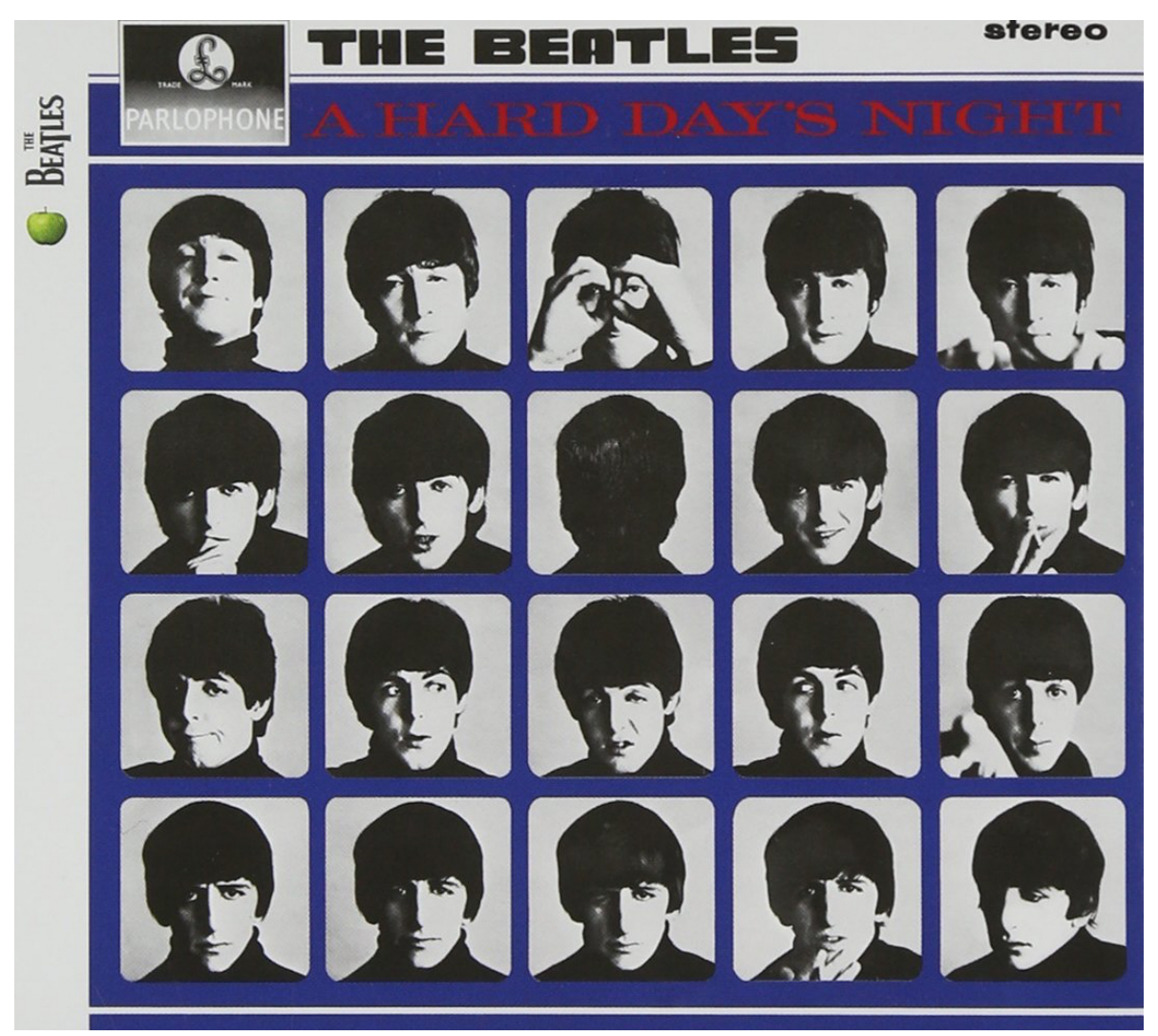

Figura 5.

A Hard Day's Night, 1964 (fotógrafo, Robert Freeman) 


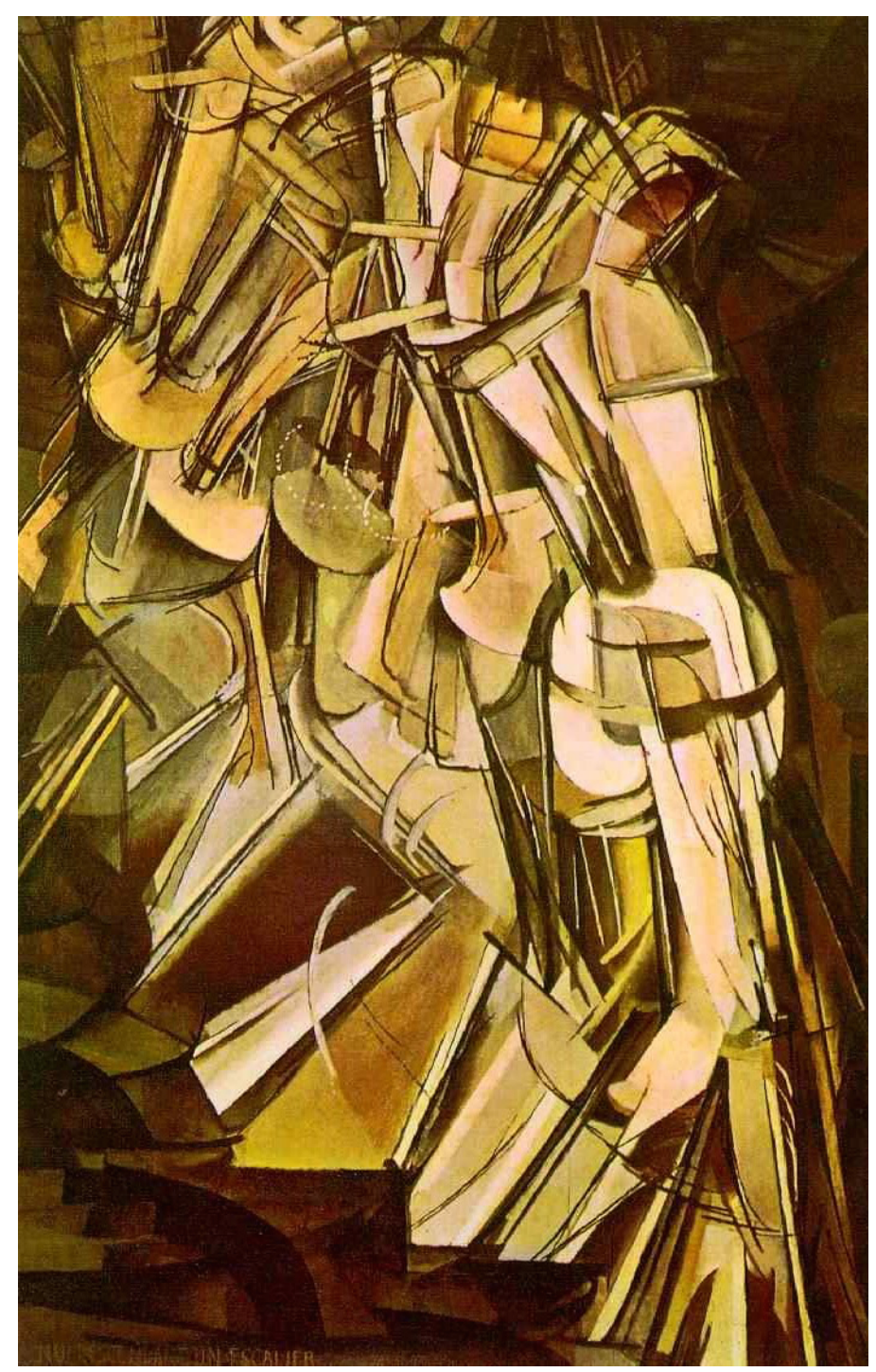

Figura 6.

Duchamp, Desnudo bajando la escalera n ${ }^{\circ} 2,1912$.

Todos los elementos artísticos glosados anteriormente distinguen a la banda de Liverpool de otros grupos contemporáneos de similares características, de hecho, la entusiasta recepción del público (hasta la actualidad) y la enorme influencia sobre los géneros populares demuestran que la fórmula del éxito beatle reside en la sinergia de distintas tendencias de vanguardia junto a ciertos elementos expresivos relacionados con la música académica.

Incluso, los temas de los The Beatles se caracterizan por un armazón armónico que concatena música y texto, realzando el contenido de la letra a partir de procesos sumamente calculados, en su mayoría, marcados por el hábil uso del cromatismo, es decir, de la dominante secundaria. Pero tal vez tengamos que remontarnos en el tiempo para comprender, en toda su magnitud, la importancia del fenómeno de las notas cromáticas y, sobre todo, su gran trascendencia en la emoción que suscita la música en el corazón humano, en el afecto, en el ethos. 


\section{LA EXPRESIVIDAD A TRAVÉS DE LAS NOTAS ALTERADAS O CROMÁTICAS}

Las notas cromáticas existen desde los orígenes de la música, desde los tiempos de la antigüedad grecolatina, de hecho, la etimología de la palabra, chroma, procede de la lengua griega ${ }^{4}$. A partir del descubrimiento del monocordio por parte del círculo pitagórico, en torno al año 500 a.C., fue posible desentrañar la serie acústica que posibilitó, posteriormente -obsérvese la Figura 7-, la formación de escalas (diatónicas) y la aparición, a causa de estas leyes acústicas, de ciertas notas alteradas -armónicos siete y once- que hacen entrever el sistema tonal como posteriormente se constituyó, dado que estos sonidos se cuentan como alteraciones necesarias en las tonalidades vecinas (fa mayor y sol mayor, respectivamente) a do mayor, la escala diatónica por excelencia 5 .

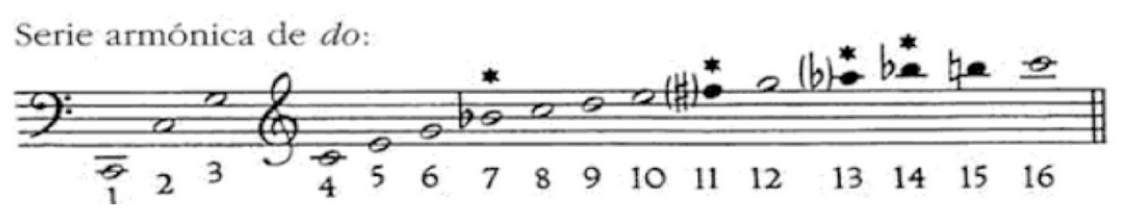

Figura 7.

Serie armónica de do, primeros dieciséis armónicos (Grabner, 2001).

De este modo, desde un sistema intuido, quasi tonal, pero en ningún caso extendido ni estandarizado, el fenómeno de las notas cromáticas convivió con el diatonismo hasta el final del Renacimiento y, paradójicamente, fue en este punto, en los albores del Barroco, justo cuando la estética musical propició un reordenamiento vertical de la armonía a través de la formación de acordes y del bajo continuo -apartando la idea de la polifonía de tipo horizontal- cuando la teoría armónica, primitivamente funcional todavía, auspició el advenimiento de un incremento del cromatismo a todos los niveles, tanto en el canto monódico como en el acompañamiento a base de acordes marcados por la cifra.

La famosa "teoría de los afectos", que propugnaba, en efecto, la manipulación de los sentimientos del oyente a través de los afectos realzados del texto en todo momento por la música, hizo posible el género del madrigal, de gran componente cromático a nivel musical y con enorme éxito de público: los textos de origen petrarquista y la música de los defensores de la llamada seconda practica (Peri, Caccini y, sobre todo, Monteverdi) junto con la aparición de la ópera a comienzo del siglo XVII, facilitaron el incremento de las notas alteradas como herramienta de expresividad en el discurso ${ }^{6}$.

De esta forma, gracias al progresivo asentamiento del sistema tonal, se desarrolló esta arquitectura armónica de tipo vertical influenciada, a gran escala, por la aparición de diversos cromatismos de tipo horizontal -es decir, a nivel melódico o lineal-, otorgando al discurso musical una enorme gama de colores - de nuevo, chroma - que realzaban la afectividad del texto, pero cuya sonoridad se alejaba, por otro lado, de la noción funcional de la armonía en favor de una progresión armónica más imaginativa y sorprendente, en suma, más expresiva, que podría compararse con la música de la segunda mitad del siglo XIX, incluso, con las vanguardias modernistas neo-tonales hasta 1945.

A continuación, podemos observar un ejemplo en Kühn (2007), en la Figura 8, sobre la obra de Monteverdi, Piagne e sospira, procedente de Il Quarto libro de madrigali a cinquevoci, publicado por primera, vez en Venecia (1603):

Un lenguaje rico en afectos queda reproducido por una música de gran riqueza afectiva: el llanto se ve reflejado en Monteverdi a través del cromatismo, y el suspiro, imitado por el silencio que interrumpe el ascenso cromático, en tanto que la huida recibe un trazo de rápidas corcheas. El resultado del cromatismo lineal es la increíble serie de armonías, sol menor, Mi mayor, la menor, Fa mayor, La mayor (armónicamente hablando, uno cree hallarse doscientos años después) (Kühn, 2007, p. 49). 

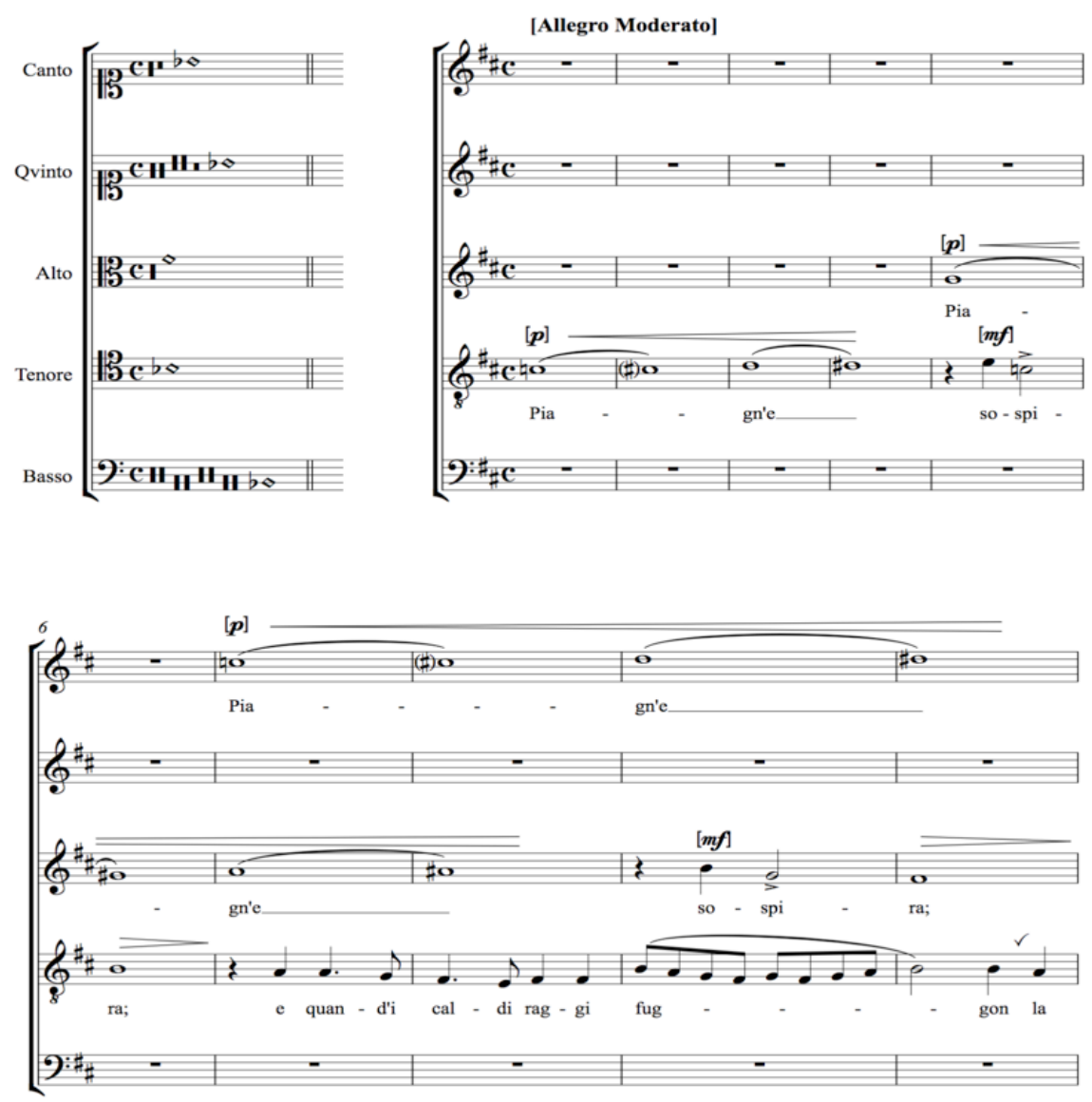

Figura 8 .

Monteverdi, Piagne e sospira, cc. 1-10.

Por tanto, en la evolución del sistema tonal -y en la paralela consolidación de la afinación temperada- los antiguos modos medivales coloreados por la musica ficta cayeron en desuso, tanto para el uso melódico como para el armónico, conservándose solo dos, los modos mayor (jónico) y menor (eólico), cuya diferenciación principal reside en el primer intervalo de tercera -mayor o menor, respectivamente- generado desde la nota de la tónica, la que da nombre a la escala. De esta manera, se puede apreciar hasta qué punto era importante para los compositores del primer Barroco buscar la expresividad desde los mismos intervalos y, particularmente, desde el uso de las notas cromáticas, dado que el modo menor que no surge de la serie armónica se deduce por analogía del mayor, de ahí sus distintas variedades ${ }^{7}$.

Aportamos otro ejemplo de Monteverdi en la Figura 9, el famoso Lamento de l'Arianna, perteneciente a la ópera homónima L'Arianna (1608) cuya partitura se ha perdido, sin embargo, fue tal el éxito de este fragmento a causa de su intensidad afectiva cercana al madrigal, que, en efecto, fue publicado aparte en el VI Libro de madrigales en 1614, de ahí, afortunadamente, su conservación para la posteridad. "The recitative reflects a variety of thougth and feeling of the text, yet maintains a remarkable continuity and homogeneity throughout. It demonstrates both the expressive power of Monterverdi's recitative, and his form-giving harmonic control" (Crocker, 1986, p. 237) ${ }^{8}$. 


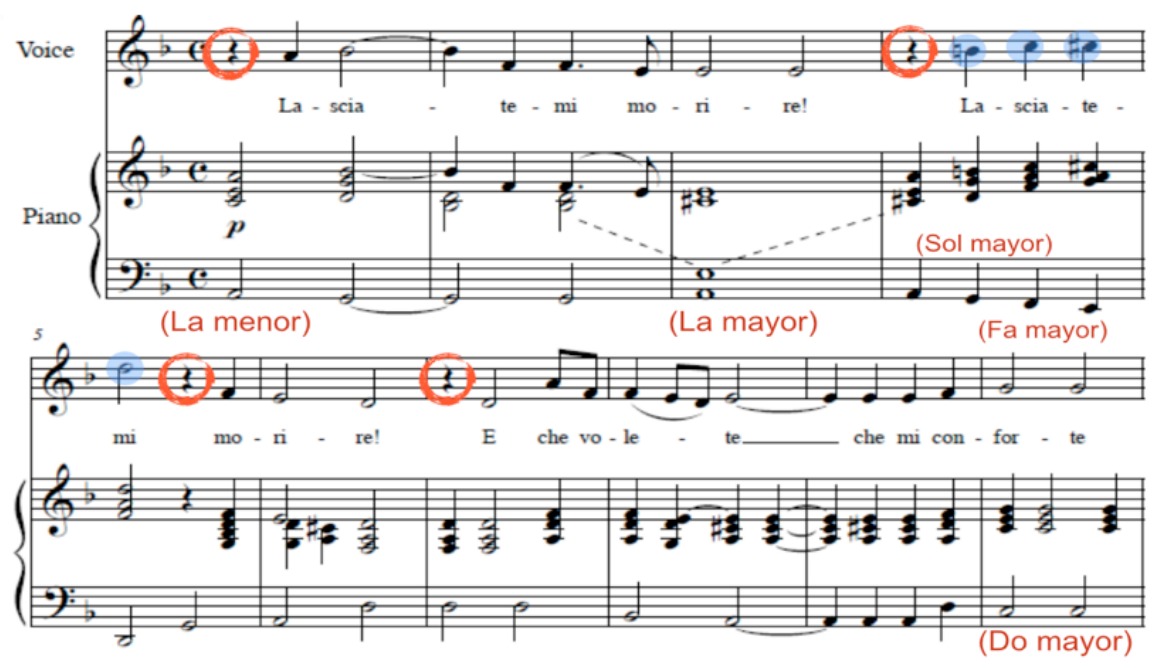

Figura 9.

Monteverdi, Lamento de L'Arianna, cc. 1-10 (reducción para voz y teclado).

En la figura anterior podemos apreciar cómo las tonalidades marcadas en rojo no pertenecen a la tonalidad principal, re menor, ni siquiera la mayor, dado que no resuelve en su correspondiente tónica. Asimismo, se puede observar la intensidad en el ascenso cromático de la segunda repetición del texto, lasciate mi morire, sustentado por una armonía construida por movimiento contrario según la dirección del bajo continuo, pasaje que contiene dos acordes paralelos, sol mayor y fa mayor, y finalmente, la cadencia sobre la tónica.

A partir de la segunda mitad del siglo XVII la consolidación del sistema tonal y la progresiva desaparición de los compositores de la seconda practica racionalizó el uso de las alteraciones y, sobre todo, de la práctica de la modulación, es decir, del cambio de tonalidad para el cual se utiliza, como mínimo, una nueva alteración. No obstante, el género de la ópera -como en la actualidad, el más prestigioso a causa de su despliegue de medios y de su fusión de ramas artísticas en un mismo espectáculo- propició nuevas incorporaciones cromáticas a la armonía tradicional en su búsqueda incansable de la expresividad que pronto, a causa de la popularidad del género, pasaron a la música instrumental: este es el caso del acorde de sexta napolitana.

Sin duda alguna, este elemento procede de la ópera napolitana del siglo XVII, de ahí su nombre, y supone una sustitución en un contexto cadencial del tradicional acorde de predominante (Bartoli, 2001) por otro de base cromática, un segundo grado rebajado, más expresivo que cualquier subdominante de naturaleza diatónica.

Podemos apreciar su intensidad afectiva en uno de los primeros ejemplos conocidos, la ópera Jephté (1648) de Carissimi -Figura 10- donde se encadenan dos napolitanas seguidas en un pasaje secuenciado, si bemol en tonalidad de la menor y, a continuación, mi bemol en tonalidad de re menor, vecina de aquella: 


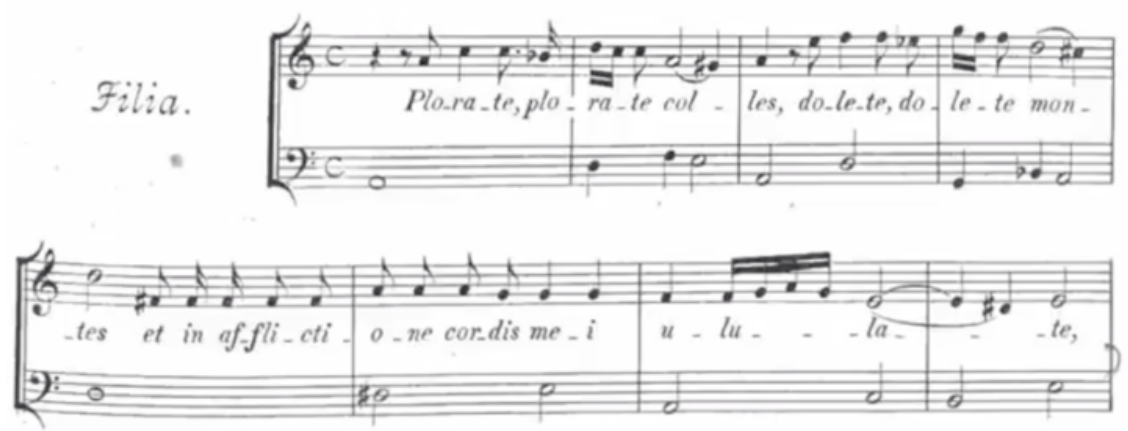

Figura 10.

Carissimi, Jephté.

De la ópera napolitana del siglo XVII, el acorde napolitano pasó a la música instrumental e, incluso, un compositor como Schubert al inicio del siglo XIX lo consideraba símbolo de muerte y aciagos presagios, vista su recurrente presencia en Die Schöne Müllerin y Winterreise y, también, en la música puramente instrumental, como se aprecia en la Figura 11:

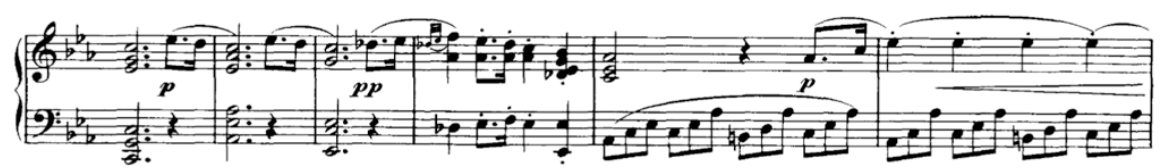

Figura 11.

Schubert: Impromptu D. $899 n^{\circ} 1$.

5. Cromatismo, dominante secundaria y expresividad... De Beethoven a The BeATLES

A comienzos del siglo XVIII -la afinación temperada solo se había extendido, verdaderamente, en torno a $1800^{9}$ - el sistema tonal se había establecido en la música occidental (Gauldin, 2009), en buena parte, gracias a la ordenación simétrica de las tonalidades mayores y menores en un figurado círculo de intervalos de quinta (o de cuarta, su inversión). También se había consolidado, desde la segunda mitad del siglo XVII (De la Motte, 1998) un sistema para cambiar de tonalidad, necesario también para la articulación de la forma musical, sobre todo, las áreas armónicas vecinas con diferencia de una alteración entre ellas, de ahí el papel fundamental de la dominante secundaria ${ }^{10}$.

Así pues, el mecanismo de la dominante secundaria regulaba la aparición de las notas alteradas con función armónica según la dirección de la modulación en el círculo de quintas - marcha [armónica], define Riemann (1913) -, bien para el lado de la dominante (desde do mayor, hacia sol mayor, añadiendo el fa sostenido), bien para el lado de la subdominante (desde do mayor, hacia fa mayor, añadiendo el si bemol ${ }^{11}$ ). Con el paso del tiempo, incluso, esta dominante secundaria tomó diversas formas armónicas en función de las notas alteradas y agregadas al acorde -séptima de dominante, sexta aumentada, séptima disminuida, novena de dominante-, fruto de la ampliación de las diversas áreas armónicas secundarias, es decir, separadas de las de la tónica inicial y final en una obra.

Por tanto, el uso de estas dominantes secundarias fue minuciosamente dosificado por los compositores a través de la forma musical y del estilo que permanecían, con todo, ligadas a la articulación de la forma y a su herramienta fundamental, la cadencia. De este modo, la dominante secundaria podía ser anexada a uno de los grados fundamentales de la tonalidad, sobre todo, el quinto grado -o el cuarto, en menor medida-, o bien, 
de manera puntual, como mera flexión en el discurso a un grado de menor importancia, segundo, cuarto, sexto y, más raramente, a causa de la noción de función, tercero y séptimo. Como se habrá podido intuir, esta regulación de las notas alterada buscaba, frente a la armonización quasi libre del Barroco, dar cabida a distintos colores armónicos mediante normas funcionales fijas dentro del sistema unitario ordenado según el círculo de quintas ${ }^{12}$ :

De este modo, bajo el yugo de la tonalidad, las notas cromáticas debían tener una función estructural permanente -más allá de cualquier nota extraña alterada, de tipo melódico-, bien en el caso de una modulación larga y formalmente definida, viaje a la dominante desde el tono mayor y al relativo mayor desde el tono menor, bien en el caso de la aparición de una dominante de otro grado de la escala sin pretensiones de modulación y dotada, simplemente, de función expresiva. En el primero de los casos, las marchas de modulación estaban definidas por la forma musical; en el segundo, los compositores dosificaban su presencia con el fin de reservarlas para un momento especialmente expresivo, por ejemplo, el punto culminante en el desarrollo de la sonata.

Entre los innumerables ejemplos de dominante secundaria que podemos observar en la música académica elegimos, tal vez, el más famoso, procedente de la Novena Sinfonia Op. 125 de Beethoven (Figura 12), cuyo último movimiento contiene un fragmento coral sobre la Oda a la Alegría de Schiller ${ }^{13}$, de larga transcendencia para la música culta posterior y, también, para la música popular del siglo XX. Se trata de un tema arquitectónicamente sencillo con forma $\mathrm{ABA}^{\prime}$, en donde el fragmento previo a la recapitulación del tema inicial - precedido por un pedal de dominante, en azul, al que sigue una serie de quintas, en rojocontiene un patrón funcional arquetípico (II-V-I), iniciado por la sensible (la sostenido) del sexto grado (si menor), punto hacia el que gira el discurso puntualmente -este si menor representa un acorde puente como segundo grado de la dominante y sexto de la tónica, de ahí la equivalencia VI=II, tiene función en ambas tonalidades, re mayor y la mayor-, resolviéndose sobre la dominante secundaria $(\mathrm{V} / \mathrm{V})$ con una síncopa de gran efecto sobre la dominante $(\mathrm{V})$ hacia la recapitulación del tema. 

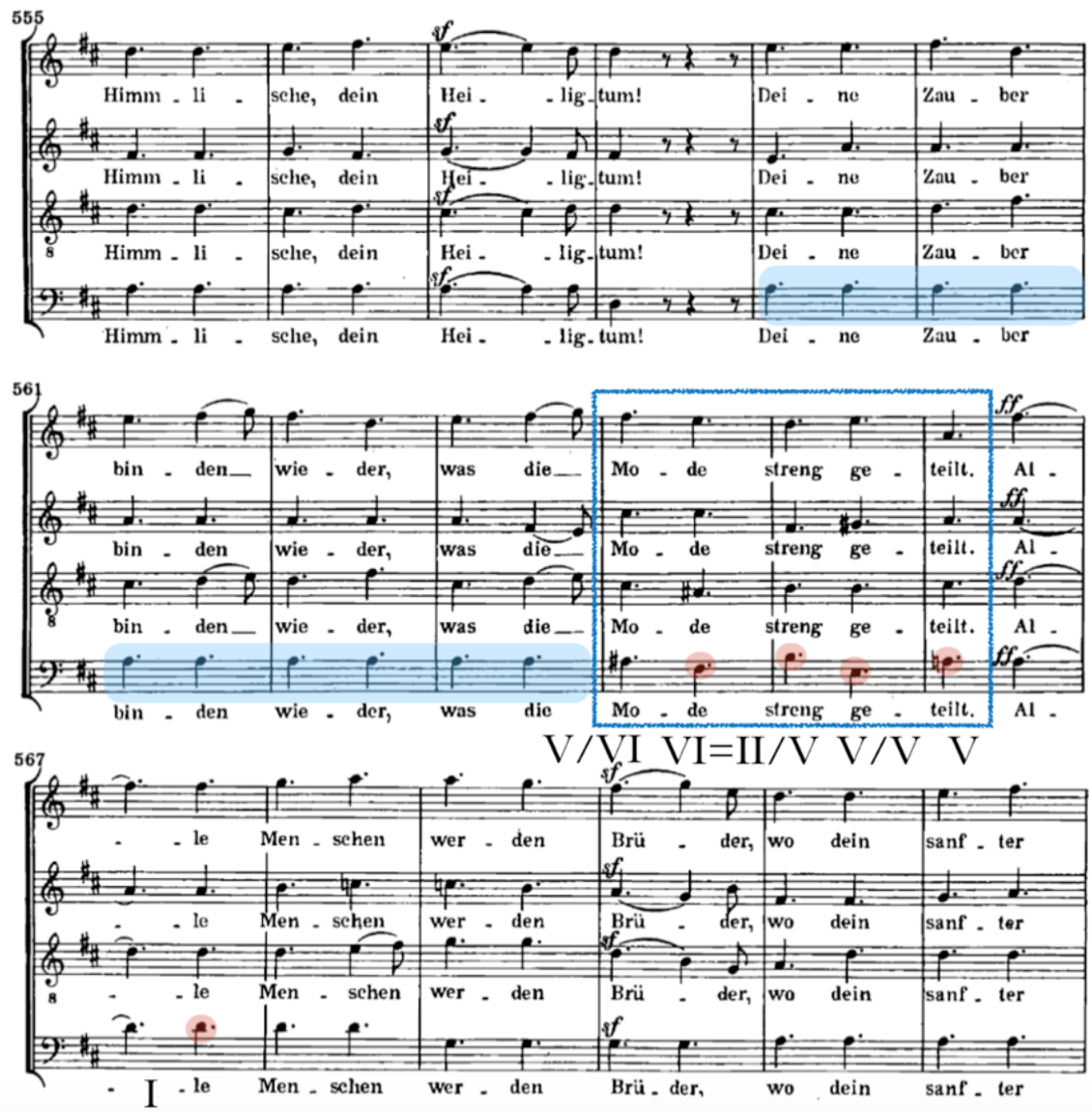

Figura 12.

Beethoven, Novena Sinfonia Op. 125, IV, cc. 555-572.

Este pasaje coincide, casualmente, con un fragmento textual de gran significado:

Deine Zauber binden wieder, $\mathrm{Tu}$ hechizo une de nuevo

Was die Mode strenggeteilt; lo que la acerba costumbre habia separado;

Alle Menschen... todos los hombres...

Un proceso semejante podemos observar en The Beatles, en cuya música regida asimismo por la armonía tradicional de tipo funcional responde a similares mecanismos, junto a la influencia de las distintas disciplinas artísticas de la época, ya comentadas.

Comenzamos nuestra exégesis con Scrambled Eggs o, mejor dicho, Yesterday, el título finalmente escogido que rotulaba el tema, el primer sencillo que interpretó un solo componente del grupo, su compositor, McCartney, con una guitarra EpiphoneTexan acompañado de un cuarteto de cuerdas, circunstancia inusual en la música pop que otorga mérito a Martin como arreglista; la orquestación fue hecha a partir de las distintas voces de la guitarra "y de las sugerencias del compositor" (Everett, 2013, p. 51); los músicos contratados para la grabación fueron instrumentistas de alto nivel en la música académica, Tony Gilbert (primer violín), Sidney Sax (segundo violín), Kenneth Essex (viola) y Francisco Gabarró (cello), este último, integrante de la London Symphony Orchestra, discípulo de Pau Casals. Esto refiere McCartney sobre el proceso de composición: "Yesterday fue un caso típico. Recuerdo que sugerí la séptima que aparece en el chelo. Él dijo: "No puedes poner eso ahí. Un cuarteto de cuerda nunca lo tocaría." “Y qué? -objeté yo-. Ponlo, George. Tiene que ir ahi'" (The Beatles, 2000, p. 175).

En este tema podemos observar el mismo caso de dominante secundaria que en la Novena Sinfonía de Beethoven, un quinto del sexto precedido de su correspondiente predominante -con equivalencia y doble 
función-, en un claro ejemplo de esquema II-V-I con la sensible (do sostenido) explicitada en la melodía. Menos académica es la otra dominante del standard, el acorde de sol mayor sobre la cadencia plagal (IV-I) que implica la omisión de la dominante principal, do mayor, en un giro típico del blues, la secuencia V-IV-I, denostada por los clásicos, que se deduce en la Figura 13:

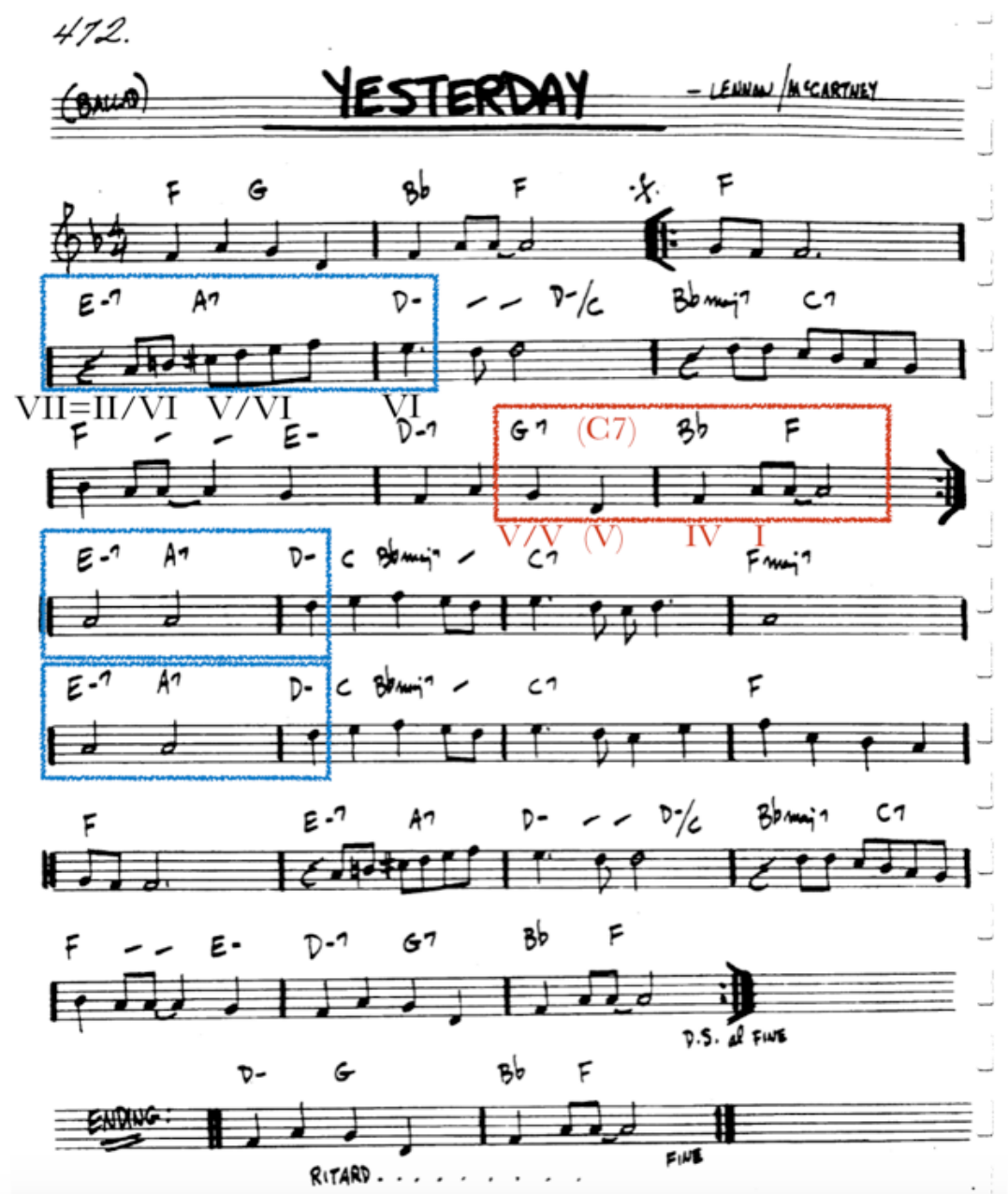

Figura 13.

Lennon y McCartney, Yesterday.

La aparición de la dominante secundaria sobre el sexto grado es un elemento recurrente en el transcurso del tema, de hecho, actúa como leitmotiv afectivo en el relato de las atribulaciones del protagonista, el desamor, el abandono de la amada, los propios errores, etc., así pues, la nota alterada (do sostenido) surge siempre en un punto estructural importante, el inicio de la frase tanto de las estrofas como del estribillo, resaltando las palabras clave: troubles, half the man y, sobre todo, la figura de la amada, she -obsérvese en la Figura 14-: 


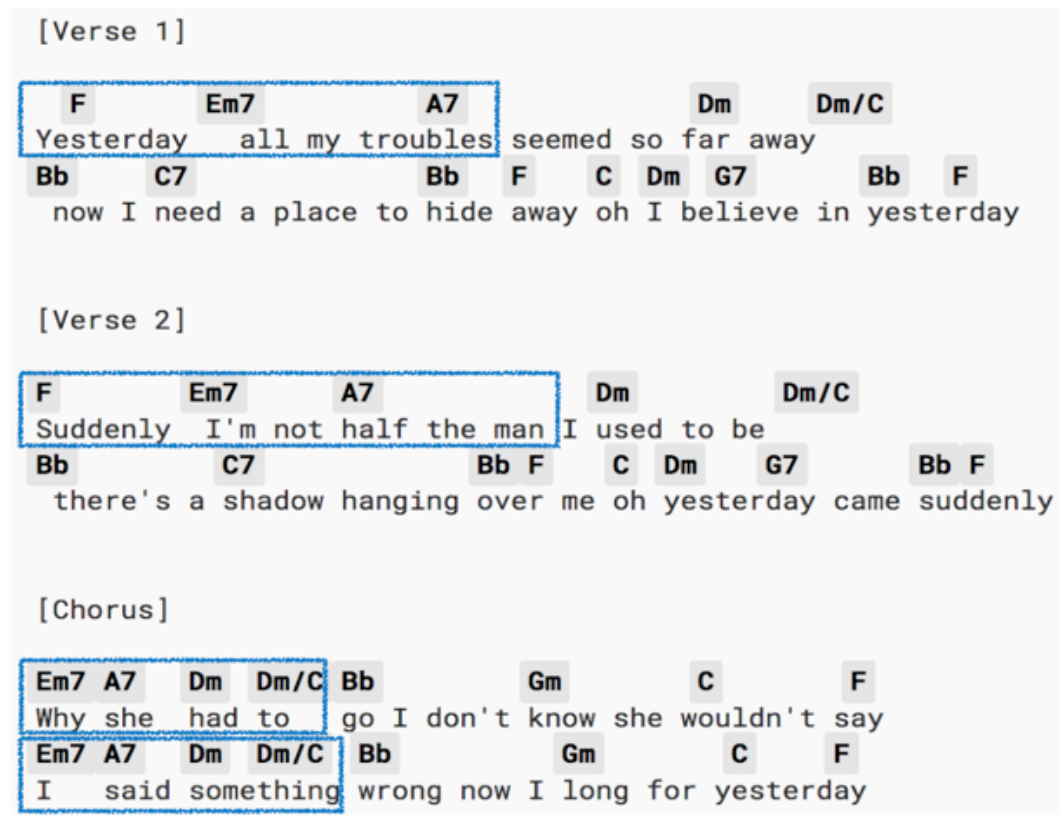

Figura 14.

Lennon \& McCartney, Yesterday.

Observamos un ejemplo semejante en otro de los temas emblemáticos de la banda, All you need is love, el single editado el 7 de julio de 1967 y compuesto por “Lennon (1.00)" (Dowlding, 1995, p. 180) para la gala donde:

Los Beatles fueron invitados para representar a Inglaterra en uno de los catorce segmentos de los países participantes de la primera emisión satelital global en vivo, llamada “OurWorld” [...] Martin [...] decidió arreglar para dos trompas una mezcla del comienzo de la invención para teclado en Fa mayor de Bach [...], el arreglo de Glenn Miller para dos saxos tenores de "In a Mood" y "Greensleeves" para chelos y violines. En buena medida, escribió las partes de los metales, duplicando sus octavas de piano, para "Le Marseillaise", como una fanfarria introductoria [...] (Everett, 2013, p. 191).

En esta canción, la dominante secundaria también ejerce de elemento reiterativo, pero de una manera distinta que en el tema anterior, dado que el acorde alterado y su carga afectiva se utilizan para remarcar, por tercera vez, un mensaje repetido - all you need is love- que desemboca en una nueva sorpresa tras la dominante secundaria (de nuevo, quinto del sexto): la inversión de la estructura de la frase junto con su resolución sobre la tonalidad principal, love is all you need.

Estructuralmente, este fragmento pertenece al estribillo donde más que la mera repetición de la frase señalada anteriormente -como en temas menos elaborados, por ejemplo, Yellow Submarine-, podemos apreciar la calculada gestión, tanto a nivel musical como textual de un material reducido y sencillo que, sin embargo, frente al peligro de la monotonía, siempre aparece variado, como se aprecia en la Figura 15: 

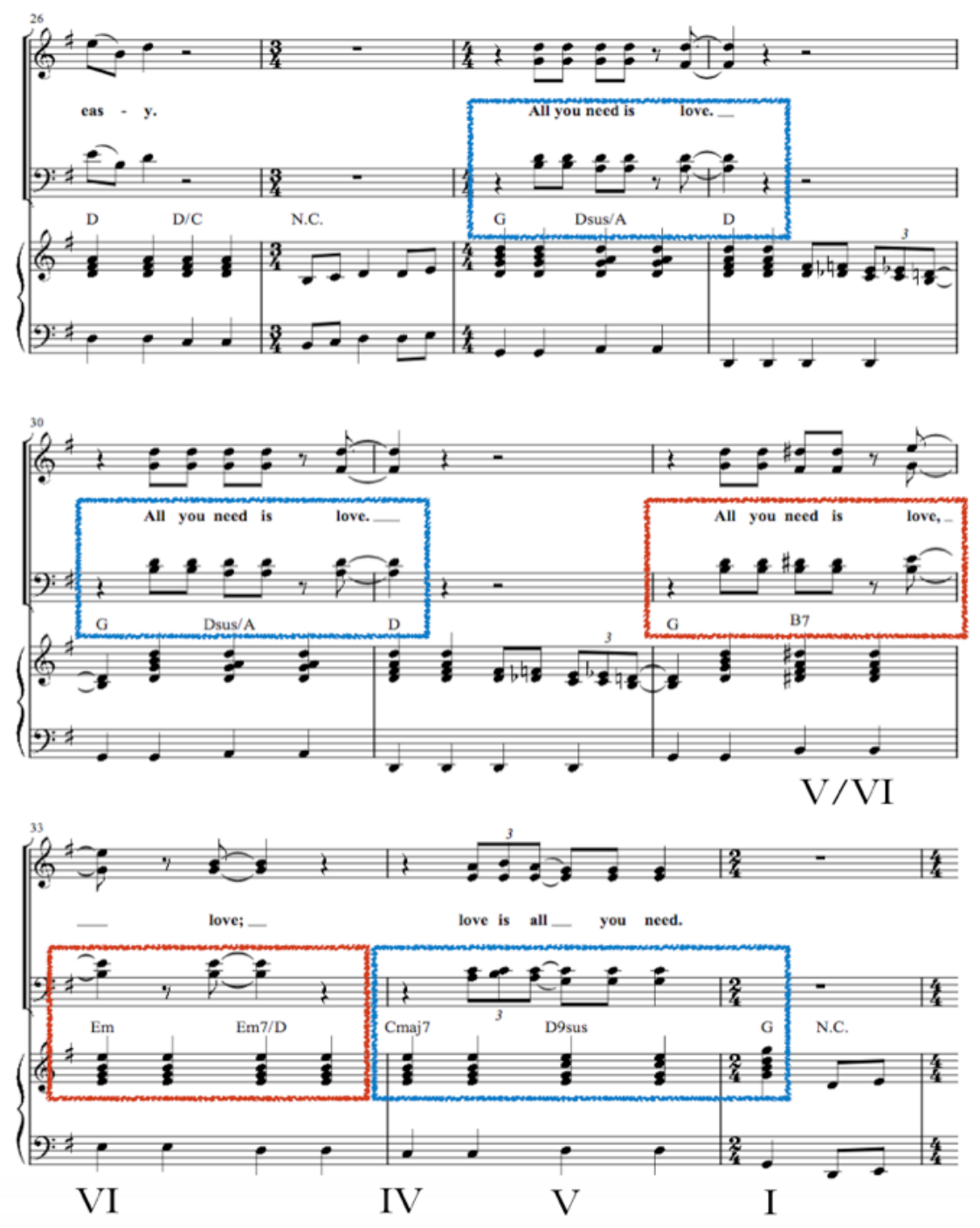

Figura 15.

Lennon, All you need is love.

Hey Jude, "McCartney (1.00)" (Dowlding, 1995, p. 200) fue publicado como single el 26 de agosto de 1968. Paul escribió el tema pensando en Julian Lennon, el hijo de John y Cynthia, como consuelo por la separación de sus padres; finalmente, McCartney cambiaría Jules por Jude: "uno de los personajes de [la película] Ocklahoma se llama Jud [...]" (The Beatles, 2000, p. 297).

La característica de "Hey Jude” más comentada es su extensión de 7’11”, que la hace el single más largo de todos los tiempos en el puesto $\mathrm{n}^{\circ} 1$, resultado de diecinueve interpretaciones de cadencia doble-plagal, un mantra de cuatro minutos sin palabras [...] (Emerick y Massey, 2011, p. 282).

De nuevo, la dominante secundaria actúa como refuerzo del texto - and any time you feel the pain-, mientras el estribillo se inicia, precisamente, con la nota alterada en la línea de la melodía, gracias a la aparición del quinto del cuarto y su correspondiente resolución en la subdominante, a continuación, en la Figura 16: 


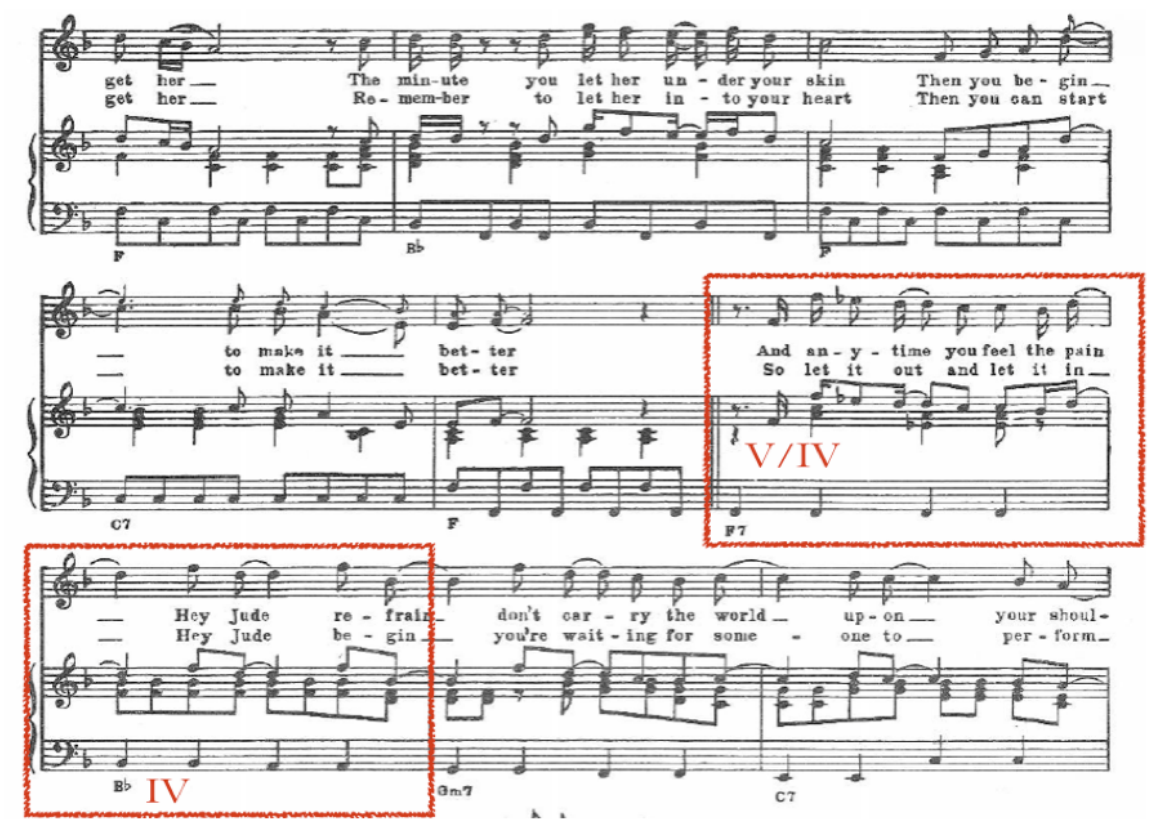

Figura 16.

McCartney, Hey, Jude.

Finalmente, dos años después de la separación de The Beatles en 1972, Lennon publicó Imagine, un tema que se convirtió en un himno pacifista universal "cuyo título está inspirado en el libro de poemas de Yoko, Grapefruit" (Julià, 1996, p.136). Las letras, por su parte, fueron siempre sinceras consigo mismo y comprometidas con la causa social, "sus deseos por la paz mundial, su apoyo a las libertades políticas, su abierto feminismo antes de que fuera una postura aceptada y su creencia en una profunda espiritualidad individual le dieron gran significado social a su música en solitario [...]” (Everett, 2013, p. 406).

De igual manera, tras una estrofa, la primera simple y diatónica -el motivo cromático que abre el tema, incluso, parece una inversión de lo observado en el estribillo de All you need is love-, el estribillo de Imagine que presenta el mensaje más poderoso de la canción (You may say, I'm dreamer..., but I'm not the only one), viene realzado, de nuevo, por la aparición de la dominante secundaria, en este caso, quinto del sexto, que, sin embargo, no resuelve sobre sobre la tónica esperada, la menor, sino sobre el sexto grado de esta, fa mayor, es decir, en una cadencia rota o evitada de gran efecto expresivo (Figura 17): 

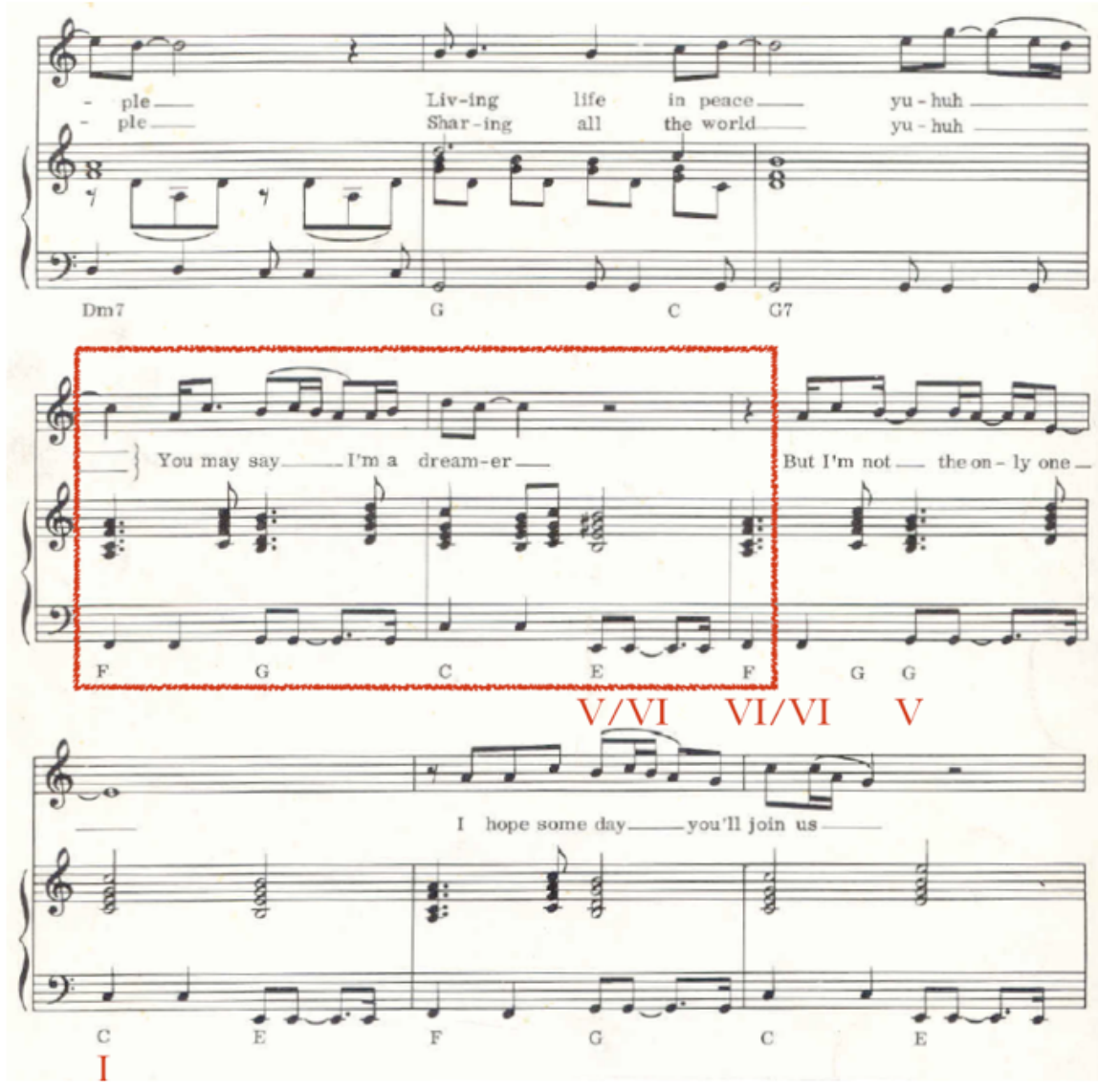

Figura 17.

Lennon, Imagine.

Por tanto, en conjunción con el texto, la dominante secundaria, es decir, la noción afectiva de la nota cromática regulada por el sistema tonal de tipo funcional, aporta una gran expresividad que realza el texto elegido por el compositor, tal y como veíamos en Monterverdi a comienzos del siglo XVII y, asimismo, en Schönberg, uno de los compositores más importantes de la primera mitad del siglo XX, quien reconocía en sus tratados pedagógicos la importante presencia de la dominante secundaria (de ahí su consejo de utilizarla con cautela): "No me cansaré de prevenir otra vez al alumno del empleo excesivo de las dominantes secundarias" (Schonberg, 1974, p. 212).

Ahora, en este punto, se advierte que en The Beatles una de las virtudes de sus canciones reside -al margen de efectos electrónicos- en la hábil introducción de la dominante secundaria en el discurso musical, sobre todo, en temas más bien lentos, alejados de la forma típica del blues, pero con una clara vocación expresiva influenciada por la música académica y la tradición afectiva de la nota cromática, de ahí, probablemente, el éxito de su música más allá de los países angloparlantes, donde se recibe con más intensidad, en general, la parte musical del tema que la parte textual.

\section{Conclusiones}

De esta manera, en la música de The Beatles podemos observar la gran influencia ejercida por diversas técnicas de la música académica -forma, instrumentación, armonía, etc.-, así como de otras tendencias artísticas: vanguardias, musique concrète, pintura, iconología, fotografía, Pop Art, cómic, etc., de ahí la vigencia de sus temas más allá del éxito internacional de sobra conocido. 
La continua búsqueda expresiva de la música de The Beatles sumado a su afán de experimentación, sin apartar, por otro lado, los preceptos eternos de la música, como se ha demostrado, hacen de la obra de The Beatles no solo un icono de la música pop de todos los tiempos, sino también un crisol de tendencias innovadoras que revolucionaron el panorama de la época y marcaron el camino del futuro, cuya huella, en realidad, permanece hasta el día de hoy.

Probablemente, en esa síntesis perfecta entre vanguardia y tradición se halla la verdadera esencia del grupo que, pese a todas las parafernalias estéticas del momento, supo aprovechar los diversos mecanismos musicales procedentes de la música seria, elucidados en estas líneas -sobre todo, en cuanto al manejo de la expresividad, según una larga tradición musical-, para llegar a un público vasto y variado -más allá del consumo adolescente- cuya fascinación por la banda de Liverpool se mantiene en la actualidad.

\section{REFERENCIAS}

Bartoli, J. P. (2001). L' harmonie classique et romantique. Paris: Minerve.

Bianconi, L. (1991). Historia de la Música. El siglo XVII. Madrid: Ediciones Turner.

Crocker, R. (1986). A History of Musical Style. New York: Dover.

De la Motte, D. (1998). Armonía. Barcelona: Idea Books.

Dowlding, W. (1995). The Beatles. Guia Completa de canciones. Madrid: Celeste Ediciones.

Dyson, G. y Drabkin, W. (2001). Chromatic. Grove Music Online. London: Oxford University Press.

Emerick, G. y Massey, H. (2011). El sonido de los Beatles. Memorias de su ingeniero de grabación. Barcelona: Ediciones Urano, S.A.

Everett, W. (2013). Los Beatles como músicos. De Revolver a la Antología. Buenos Aires: Eterna Cadencia Editora.

Gauldin, R. (2009). La práctica armónica en la música tonal. Madrid: Akal.

Goldman, A. (2010). Las muchas vidas de John Lennon. Barcelona: Editorial Lumen.

Grabner, H. (2001). Teoría general de la música. Madrid: Akal.

Harnoncourt, N. (2006). La música como discurso sonoro. Barcelona: Acantilado.

Heard, G. (1993). Pintura y escultura en Europa: 1880-1940. Madrid: Cátedra.

Hertsgaard, M. (1995). Los Beatles. Un día en la vida. Barcelona: Grijalbo.

Julià, I. (1996). John Lennon. Valencia, España: La Máscara.

Kühn, C. (2007). Tratado de la forma musical. Madrid: Mundimúsica.

Lennon, C. (2006).John. Barcelona: Ediciones Robinbook.

Mann, W. (2008). The Beatles Bible. The Times: What Songs The Beatles Sang. Gales, Reino Unido. Recuperado de https://www.beatlesbible.com/1963/12/27/the-times-what-songs-the- beatles-sang-by-william-mann/

Panofsky, E. (1972). Estudios sobre iconología. Madrid: Alianza Universidad.

Riemann, H. (1913). Armonia y modulación. Barcelona: Labor.

Seguí, S. (1991). Teoría musical, volumen II. Madrid: Unión musical española.

Schoenberg, A. (1974). Tratado de Armonía. Barcelona: Labor.

The Beatles. (2000). The Beatles Anthology. San Francisco: Chronicle Books LLC.

\section{Notas}

1 "Si pensamos en la música actual, observamos enseguida que está dividida: diferenciamos entre música popular, música ligera y música seria" (Harnoncourt, 2006, p. 22).

2 En lo sucesivo, los números hacen referencia al porcentaje de autoría referido por Dowlding (1995). 
3 Pero el interés armónico también es típico de sus canciones más rápidas, y uno tiene la impresión de que piensan simultáneamente en armonía y melodía, tan firmes son las séptimas y novenas mayores de tónica, incorporadas en sus melodías, y la modulación por submediante, tan natural como la cadencia eólica al final de Not a Second Time (la progresión de acordes donde termina Song of the Earth de Mahler) (traducción de las autoras).

4 Véase Gauldin (2009): "la armonía cromática proporciona una paleta tonal más amplia, con la que se puede enriquecer o colorear melodías o armonías diatónicas. El término cromático se deriva de la palabra griega chroma, que significa color" (p. 413).

5 Desgraciadamente, la música de Grecia nos ha llegado - por motivos evidentes- de manera muy fragmentaria y, de hecho, los antiguos modos griegos pasaron a la música de la Edad Media en forma de múltiples variedades en función del lugar y de la época (Seguí, 1991). Sin embargo, ya desde el siglo XII se empezó a utilizar la expresión musica ficta (es decir, figurada, fingida), que reflejaba las notas alteradas al margen de la musica vera (verdadera), procedente del sistema hexacordal del Medioevo y, en buena medida, diatónico, a excepción del si bemol, la primera de las notas alteradas en la serie de los armónicos naturales.

6 "The diatonic-chromatic opposition is roughly analogous to the contrast between musica recta and musica ficta in medieval and early Renaissance polyphonic theory; unlike the later diatonic system, however, musica recta generally included B flat in addition to the seven 'uninflected' notes from A to G. Throughout this period notes were altered by semitone in performance, mainly to avoid vertical or melodic dissonances and to create leading-note relationships at cadences. This practice led some 20th-century commentators to speak of a 16th-century 'secret chromatic art'. True chromaticism had its first flowering in the secular music of the second half of the 16th century, above all in the Italian madrigal (Rore, Marenzio and Gesualdo), where it went hand in hand with expressive, affective text-setting. This development was transported to England in the late 16th and early 17 th centuries, and also had a profound influence on secular monody and the beginnings of opera in Italy around the turn of the 17th century" (Dyson y Drabkin, 2001, p. 89). La traducción de esta cita es: "La oposición diatónica-cromática es más o menos análoga al contraste entre musica recta y musica ficta en la teoría polifónica medieval y renacentista temprana; sin embargo, a diferencia del sistema diatónico posterior, la musica recta generalmente incluía el si bemol además de las siete notas 'no flexionadas' de la a sol. Durante todo este período, las notas fueron alteradas por semitonos, en el desempeño de evitar disonancias verticales o melódicas y crear las conducciones de voces en las cadencias. Esta práctica llevó a algunos comentaristas del siglo XX a hablar de un "arte cromático secreto" del siglo XVI. El verdadero cromatismo tuvo su primer florecimiento en la música secular de la segunda mitad del siglo XVI, sobre todo en el madrigal italiano (Rore, Marenzio y Gesualdo), donde fue de la mano con textos expresivos y afectivos. Este desarrollo fue transportado a Inglaterra a fines del siglo XVI y principios del XVII, y también tuvo una profunda influencia en la monodia secular y los comienzos de la ópera en Italia a principios del siglo XVII" (traducción de las autoras).

7 "En la especulación sobre el valor ético de cada modo antiguo pierde significado y cede el paso a la consideración de la valencia expresiva específica de cada uno de los intervalos (melódicos y armónicos), independientemente de la tonalidad de referencia, de la función de las disonancias como instrumentos eficaces de moción de los afectos (en cuanto portadores de perturbaciones pasajeras y, de repente, compuestas desde el orden consonante, y, en fin, de la fuerza expresiva de las modulaciones" (Bianconi, 1991, p. 55).

8 El recitativo refleja una variedad de pensamientos y sentimientos del texto, pero mantiene una notable continuidad y homogeneidad en todo momento. Demuestra tanto el poder expresivo del recitativo de Monterverdi como su control armónico y formal (traducción de las autoras).

9 El monumental Clave bien temperado de Bach, un doble repaso por las veinticuatro tonalidades mayores y menores, tenía que ser, necesariamente, una obra para clavecín o algún otro instrumento de teclado dada la variedad de afinaciones en los instrumentos de la época y la limitación a las notas de los armónicos naturales de los instrumentos de viento metal.

10 La dominante secundaria también se puede encontrar como dominante aplicada, dominante anexada, dominante de cambio... La terminología es inagotable en este tipo de elementos, sobre todo, en un idioma como el español al que se suelen traducir los manuales procedentes de otras lenguas, tradicionalmente, alemán y francés, si atendemos al contenido que nos ocupa, y, últimamente, del inglés.

11 Nótese que estas dos notas alteradas, si bemol y fa sostenido, aparecen en la serie armónica de la Figura 7, de ahí que la organización acústica del círculo de quintas y del sistema de modulación tenga un origen natural acústicamente hablando.

12 "Las dominantes secundarias pueden ocurrir, si la sucesión de fundamentales lo permite, en todos los sitios donde puedan estar los grados propios de la escala. Pero donde encajan mejor es allí donde haya una sucesión de fundamentales defunción similar a la dominante, a imitación del modelo V-I, V-IV y V-VI" (Schoenberg, 1974, p. 219).

13 En 1972, el Consejo de Europa convirtió el tema de la Oda a la Alegría de Beethoven en su himno. En 1985, fue adoptado por los dirigentes de la UE como himno oficial de la Unión Europea. El himno no tiene letra, solo música. En el lenguaje universal de la música, es la expresión de los ideales europeos de libertad, paz y solidaridad. Recuperado de https:// europa.eu/european-union/about-eu/symbols/anthem_es 
Todos los derechos reservados. Universidad de Costa Rica. Esta revista se encuentra licenciada con Creative Commons. Reconocimiento-NoComercial-SinObraDerivada 3.0 Costa Rica. Correo electrónico: humanidades@ucr.ac.cr/Sitioweb: http: //revistas.ucr.ac.cr/index.php/humanidades

CC BY-NC-ND 